\title{
The Effect of Making a Derived Food Choice for a Relevant Other on the Pre- Fulfillment of One's own Health Goal
}

Heinz, Susann Kathrin ${ }^{1}$

\begin{abstract}
The aim of this study is to clarify the question of how making a derived food choice for ones' child influences a mothers own consumption behavior of sweet snacks. The focus of this study is set upon the difference of the consumption behavior of mothers as a consequence of their selection amongst a healthy and unhealthy food alternative aimed for their child. Finding a result in line with the expectations, the study reveals that mothers who perform a derived choice of a healthy food item for their children, feel free to eat more of unhealthy products as a consequence of their family benefitting behavior. Interestingly, the mothers' consumption behavior seems to be strongly and negatively moderated by their perceived happiness in the relationship with the father and the compatibility of both partners' educational techniques.
\end{abstract}

A good mother remembers to serve fruit at breakfast, is always cheerful and never yells, manages not to project her own neuroses and inadequacies onto her children,

[...] remembers to make play dates, her children's clothes fit, she does art projects with them and enjoys all their games

\section{Introduction}

Ayelet Waldman, Novelist, Israel

Being a mother comes along with many expectations. Mothers are exposed by society to widely-known ideals regarding how a perfect mother should act, love and be. You have to be a perfect mother who always puts her children first. You have to be a caring mother who always knows advice and the right thing to say. You have to be the loving mother who wants and knows the best for her children. The drive towards perfection in parenting exposes miscellaneous pressures on mothers and their self-understanding. These pressures are even intensified in today's modern societies where access to valuable information, nutritious food and mutual help in parenting is given. Not until recently was it commonly well-known that a healthy nutrition supports children's cognitive as well a corporal development during adolescents, which in turn sets the condition for a healthy adult-life (WHO, 2011). Therefore, mothers assign more attention to the findings of current studies in order to provide their children with most beneficial food selection in

${ }^{1}$ Susann Kathrin Heinz received her bachelor degree in International Business (Marketing) at Maastricht University, The Netherlands in 2014. At the moment she takes a Masters in International Marketing at King's College London, UK.

Contact: s.heinz@alumni.maastrichtuniversity.nl or susann.heinz@kcl.ac.uk 


\section{The Effect of Making a Derived Food Choice}

order to be the most optimal mother possible (NICE, 2008, UNICEF 2010). As a result, mothers strive to select "good" groceries in the supermarket (vegetables, fruits, no preassembled food) and cook fresh and healthy meals for their youngsters aimed to satisfy their child's/children's nourishment needs. Being still indigent to parental supervision and care taking, mothers feel the responsibility of leaving the best piece for their children or eating the leftovers from yesterday so that more is left of the fresh food for the youngsters. This thinking comes along with the dictum of being a perfect mother and putting the child first. In preparation of this study, this interviews with young mothers indicated exact this pattern. The feeling of doing something good for their children (leaving the best piece for them), already gives them a feeling of satisfaction and happiness so that it is no more important that they eat healthy themselves. Consequently, it figured that young mothers perceive themselves to live unhealthier today as they did before when they only cooked for themselves and did not care about healthy food that much. Having observed this interesting pattern of mothers eating less healthy even when buying healthy groceries, led to the inspiration for conducting primary research on this topic. Therefore, this study centers around the problem of whether it is indeed true that mothers who already made a food choice, which fulfilled the health goal for their children, do no longer intrinsically hold the health goal for themselves. Some researchers already evidenced that when the attribute of living healthy is already covered, this goal is likely to be no longer a goal to pursue (Chakravarti, Janiszewski \& Ülkümen, 2006). As a result, one can derive that mothers who just bought or cooked healthy food for their children, tend to consume higher amounts of unhealthy and sweet in-between-meal snacks to satisfy their personal appetite. To elaborate the underlying process of this observation statistically, this study asks the research question of how making a food choice for a relevant other influences the own consumption behavior.

Consequently, the outline of this paper is to first shed a light on the theoretical roots of the underlying problem in order to build upon the theoretical framework as well as the experimental setting and research design. On the basis of these established concepts, the statistical results are elaborated and discussed incorporating its managerial and social implications, limitations and future research outlooks before reaching a conclusion.

\section{Literature Review}

Different studies try to explain why people make certain choices given the fact that they already made a certain product choice beforehand. To relate this idea to the topic of this study, it needs to be theoretically clarified what possibly drives mother's consumption of unhealthy snacks after supplying their children with healthy food. One explanation 


\section{The Effect of Making a Derived Food Choice}

considers the decision attributes used to select a product in the first place. Chakravarti, Janiszewski, and Ülkümen (2006) found that information used to screen among different alternatives is less likely to be considered in later decision search processes as this information was already used to screen. This phenomenon is called screening effect and states that after a first choice (selection) is made with the mean of a certain decision attribute, the same attribute is deemphasized and viewed as already been noted or satiated. Hence, screening alternatives on attributes, such as nutrition, safety, and price, may result in the neglect of these attributes in a subsequent choice such as own nutrition. Consequently, there seems to be a compensatory choice process apparent reducing the attributes importance in the second decision stage.

Furthermore, the study of Wilcox, Vallen, Block, and Fitzsimons (2009) elucidates more on the compensating character of already served attributes considered for creating a choice set. Their study focused on clarifying the question why the addition of healthy alternatives to choice sets (eg. food menu's), can paradoxically increase the consumption of unhealthy food items. So, as Keohane (2008) nicely pointed out, consumers wanting healthy meals on a restaurant menu, does not automatically imply that they also wanted to eat them. Rather goal theory explains that the mere opportunity to behave in line with a goal (attribute: healthy) - via the simple presence of a goalaligned choice option on the menu, can lead to a perceived goal satiation and a consecutive behavior inconsistent with the health goal (Wilcox, Block, Fitzsimons \& Vallen, 2009). Consequently, the decision made is depended on the context (situation), in which the choice is reached (Fishbach \& Zhang, 2008). Recent research on context dependent decision making found that more respondents made an indulgent food choice when a healthy option was present (37\%) on restaurant's menu, compared to when one was not available (17\%)(Wilcox et al., 2009). So healthy food options on the menu, make the unhealthy items on the menu appear less threatening and, hence, harder to avoid (Monin, 2007). The mere existence of a goal-consistent option is apparently already sufficient to fulfill the need of goal-consistent behavior. This idea relates to Chakravarti et al. (2006) screening effect, which says that when the attribute "health" is noted to be attainable due to having the freedom to choose this healthy food option, this goal is already satiated due to achievability.

Furthermore, Wilcox et al. (2009) showed that the existence of a healthy food option seems to provide individuals with the license to indulge and fall for tempting food options. To explain this idea let us imagine a person focusing on their progress toward a focal goal (dieting by eating no junk food). Having this long-term goal in mind and pursuing it constantly, allows them to temporarily disengage from that goal to pursue tempting alternatives (Fishbach \& Dhar, 2005; Fishbach \& Zhang, 2008). This implies that 


\section{The Effect of Making a Derived Food Choice}

individuals license themselves to indulge in temptations when previously managed to perfectly act according to their longer-term goal. This effect is nowadays known as the licensing effect (Fishbach \& Dhar, 2005; Khan \& Dhar, 2006). Even further, it is shown that already the intention to engage in virtuous activities (e.g., starting a diet tomorrow) lead individuals to select more indulgent items (eating at McDonalds) in response. The inconsistency is justified by allowing oneself a one-time inconsistency. An extreme form of this inconsistency is called the "what the hell" effect (Polivy \& Herman, 1985). Here individuals decide upon a course of behavior that is inconsistent with a goal (e.g., abandon their diet to eat a cookie), and afterwards they are likely to further continue to indulge to an even greater extent (eat entire pack) because they already behaved against their goals anyways. So research predicts that people having the goal to live healthy, eat even greater amounts of unhealthy food when they once started acting against their long term health goal.

Moreover, it can be said that eating healthy poses a constraint on people's food choice so that the desire to eat healthy competes with the wish to fulfill ones appetite (Fishbach \& Finkelstein, 2010). Wanting the best nutrition for one's family, not always aligns with the mothers very own food desires. Rather Fishbach and Finkelstain (2010) discovered that when the choice of compliance to maxims externally imposed from agents or the society, the likelihood to indulge is greater than if the choice was made freely. To transfer this thinking to our example: The goal to be a good mother and to provide the family with nutritious food, is part of mothers "job" of complying with this maxim and societal expectation. It is not a question of "would like" or "do not like" to raise my children healthy, but rather a norm. The mother's personal taste of whether she would like to eat today hamburgers with ham is not important. In order to comply with this norm to be a good mother and to put her children's health first, she neglects her own desires. In this way her personal free choice gets inhibited to favor the health of her children. Therefore, a family goal (imposed) is not necessarily understood as personal goal (freely). Rather the condition of this externally-imposed-norm-compliance affects that mothers feel even more tempted after serving the family health goal, which in turn increases their own tendency to indulge. So, people choosing a health goal for their very own fortune are more committed and intrinsically motivated to comply with it. However, externally imposed health goals are externally motivated and are weak on personal commitment. Therefore, mothers complying with a healthy nutrition because it is for their children's best, do not necessarily and personally comply with this goal themselves. So seeing the mother snacking sweets in the kitchen after preparing a healthy family meal is not uncommon. Purchasing healthy items in the grocery store and cooking fresh food, seems to signal already that the family health goal was sufficiently met, and thus it 


\section{The Effect of Making a Derived Food Choice}

increases the strength of the conflicting motive to fulfill her own appetite (Fishbach \& Finkelstein, 2010). The mere feeling of having made progress (in their family nutrition) let them experience goal fulfillment and relax their effort in pursuing that focal goal for their personal health (Carver and Scheier 1998).

This observation goes in hand with research that showed that when a certain choice option upfront had been eliminated from the evoked set, persons form a strong preference for the eliminated, no-longer-available alternative (Brehm, 1966). Consequently, when mothers feel obliged to comply with a healthy style of cooking, they are likely to react by experiencing a greater temptation for the products prohibited to them. This phenomena is generally elaborated in reactance theory (Brehm, 1966).

This conflict is even intensified by the perception that healthy food generally is less fulfilling and leaves you hungrier than when eating fat, unhealthy food (Chandon \& Wansink, 2007). So an underlying mechanism was found that eating healthy and feeling hungry are directly associated in memory (Fo"rster, Liberman \& Friedman, 2007; Neely, 1977; Van Osselaer, 2008), such that healthy eating inevitably brings to mind thoughts about feeling hungry. Studies discovered that eating healthy makes one feel hungrier compared to even not eating at all (Fishbach \& Finkelstein, 2010). Consequently, mothers keeping up their goal of nurturing their family healthily, even further increase their personal hunger for unhealthy but perceived-as-filling food.

On the basis of this related literature, one can now start elaborating on the explanation of the underlying mechanisms addressing the problem of this paper.

\section{Theoretical Framework}

Having introduced these main effects such as screening effect, licensing effect, "what the hell" effect and the reactance effect, gives a good background to build the following research on.

Therefore, relating this to the problem statement, it is expected that mothers who make healthy food choices for their children to be likely to eat more snacks than mothers do who select an unhealthy food for their kids. The following concepts described below all are subparts of the concept of "perceived health goal satiation" by the mother. The assumption that mothers perceive the health goal as already satisfied is built on the findings of studies elucidating the attribute screening effect (Chakravarti, Janiszewski \& Ülkümen, 2006). In the moment where mothers make a healthy nutrition choice, the attribute healthy should be satiated and therefore they can themselves consume an unhealthy snack afterwards. The licensing effect also further explains this pattern (Fishbach \& Dhar, 2005; Khan \& Dhar, 2006) why mothers already feel their health goal 


\section{The Effect of Making a Derived Food Choice}

as fulfilled. Having acted according to their intrinsic goal of keeping their families healthy and providing the youngsters with healthy food, mothers are likely to license themselves for personal, short-term appetite satisfaction in compensation. The reactance effect makes personal snacking even more attractive (Brehm, 1966). Complying with the socially imposed norm of being a good mother and bringing home healthy food for their children, mothers neglect unhealthy and sweet food, making it more interesting for themselves later on. By eliminating this unhealthy food option upfront, they more tempted to eat it themselves when nobody looks. Furthermore, in the moment when they already started eating from unhealthy snacks, the "what the hell" effect should occur, which increases the total amount consumed (Polivy \& Herman,1985). Due to the thinking that if they already acted against their health goal, they also can satisfy their appetite need to a high extent by eating a lot.

These effects are assumed to not appear in a situation where mothers select UNhealthy foods for their children. Therefore, mothers' consumption of in-between snacks will be lower for the ones making unhealthy family food choices in comparison to mothers making healthy choices. Thus, the following hypothesis is reached:

H1: Making a healthy instead of unhealthy food choice for their children, leads mothers to eat a higher amount of snacks in comparison to mothers who did select an unhealthy food item.

\section{Methodology and Research Design}

As the focus of this study is to elaborate on the personal consumption behavior of mothers as result of their prior performed nutrition choices for their children, the sample is also drawn from mothers only. At least 20 mothers are planned to participate in each condition. Therefore, the sample consists of 40 females with children in an age of 2-7 years. Mothers having children in this age are assumed to be most likely to still perform the nutrition choice for their children. Also children in this age are assumed to be already able to eat the same groceries as their adult counterparts. A convenience sample is used to approach the female participants of this study in German Kindergartens. In order to test of whether mothers who just performed a healthy food choice for their children tend to eat more of an unhealthy snack themselves (amount consumed=dependent variable), one setting with a twofold independent variable is created in order to increase the validity of the study. Therefore, the condition is created where participants choose between a healthy and an unhealthy food meant to be for their children. 


\section{The Effect of Making a Derived Food Choice}

Thus, the following research format with 1 binary independent variable is created: $2 \mathrm{x}$ (choice type: health vs. unhealthy)

The dependent variable "Snack Amount consumed by mother" is measured on an interval ratio scale in terms of gram of a provided snack the participants consume during the experiment. As a hidden observation is applied to detect how much of the snack participants are eating during the questionnaire filler task, quantitative research is used. The results of the conditions are analyzed with an independent sample t-test in SPSS.

Additionally, in order to control for participants hunger level (time since last meal), demographics (age, employment, etc.), happiness in current relationships to child and father (Relationships), health consciousness as well as current dieting patterns (eating habits), questions regarding these issues are included in the questionnaire and are evaluated with means of twelve ANCOVAs.

\section{Conceptual Framework}

Given this research design consisting of 1 dependent variable (snack amount consumed by mother) and 1 binary independent variable (health vs. unhealthy for the own child), a direct impact of the independent on dependent variable is assumed. Thus, it is expected that a certain type of choice for the youngsters, has an influence on the level of satiation of the mother's health goal affecting the amount consumed of an unhealthy snack by mothers. The concepts, variables and relations introduced in the theoretical framework are compressed in the following conceptual framework.

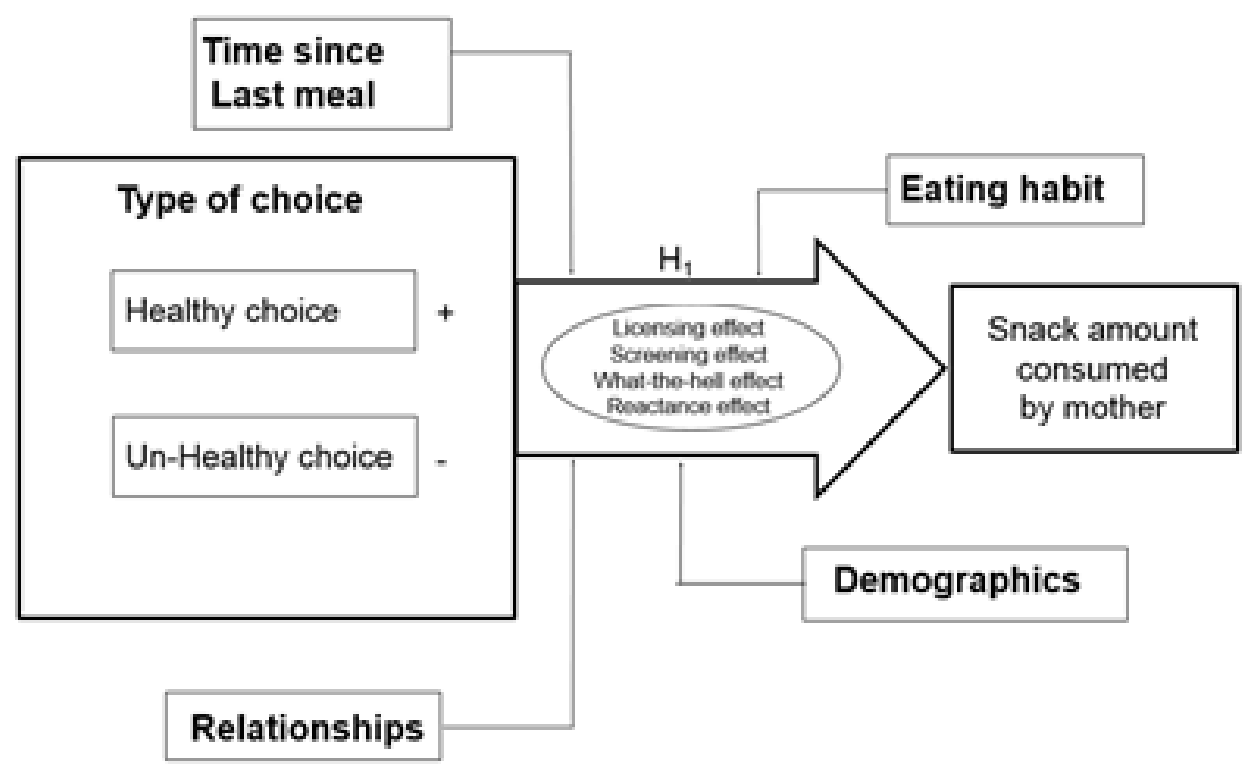

Figure 1: Conceptual framework 
Consequently, a healthy food choice is expected to have a positive effect on the mothers' health goal satiation, whereas an unhealthy snack does not saturate the perception of the mothers intrinsically hold attribute of healthy nutrition. As a result, making a healthy food choice is expected to be positively associated with a higher snack consumption by mothers, whereas a person having selected the unhealthy food item is expected to eat less of an unhealthy snack (negative relation). The concepts of the Screening effect, Licensing effect, What-the-hell effect, Reactance effect) explain the psychological concepts behind this phenomena as already described in the theoretical construct section of this paper.

Furthermore, it is assumed that participants hunger level (time since last meal), demographics (age, employment, etc.), happiness in current relationships to child or father (Relationships), health consciousness as well as current dieting patterns (eating habits) may influence the results (snack amount eaten by mothers) of the experiment in a moderating way.

Having introduced these independent, dependent, mediating and moderating variables, the experiment testing these assumptions can be performed.

\section{Experimental Design}

The experiment took place in a German kindergarten in the end of May and beginning of June. Summer time is especially good for conducting this experiment because kids are still kept playing outside before being approached by their mothers. So this facilitates that mothers can perform the product choice for their children without the youngsters' intervention.

So, at the beginning of the experiment the participants perform a product choice between two presented items (real not hypothetically), which they are allowed to take home for their children. Research of Shiv and Fredorikhin (1999) showed that certain effects only occur when the trigger is real instead of presented in form of a picture (hypothetical). Therefore, this knowledge was also used to optimize the set-up of this experiment, using real food items only. The items are presented to them on a table before they receive the questionnaire. 


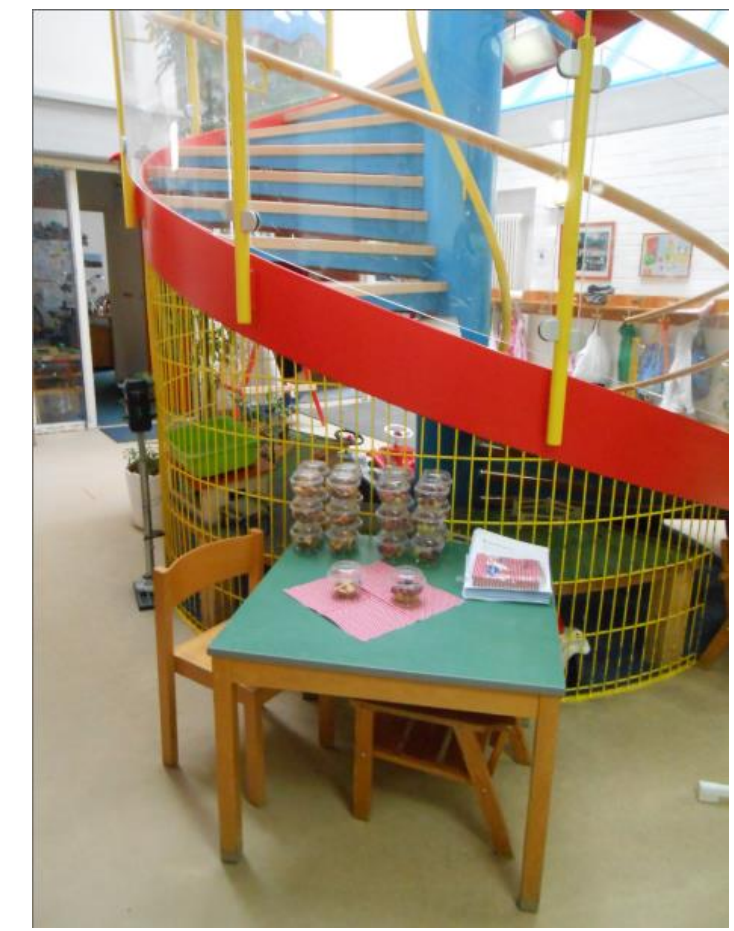

Picture 1: Choice presentation

Corresponding to the two-fold condition a choice is made either for a healthy or unhealthy snack for the own child. It is important that this selection among the two options is made without the child being present.

Therefore, mothers choose between a container of grapes and chocolate cookies as a take-away for their children at home. Both food options are packed in re-closable, transparent, plastic containers and filled with either a mix of seedless, green and red grapes (healthy) or Leibniz cookies with a chocolate crust (unhealthy).

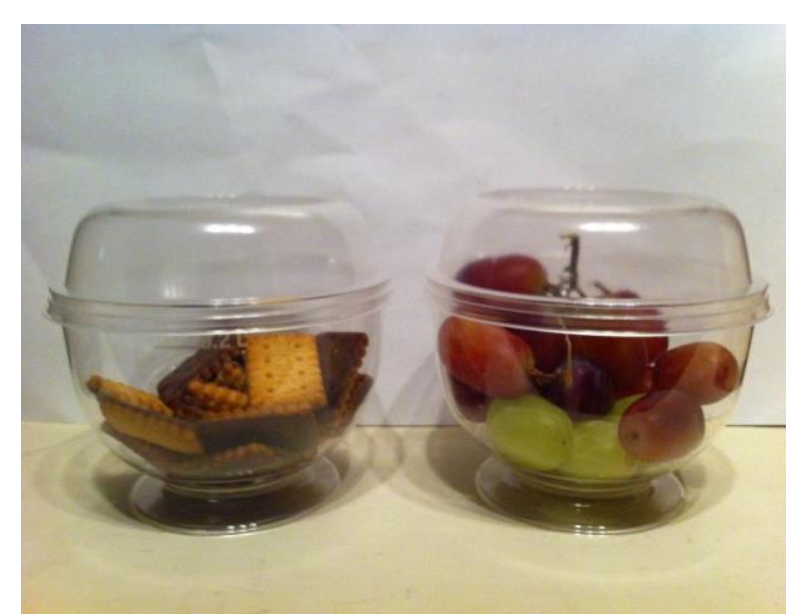

Picture 2: Cookies and Grapes in plastic containers

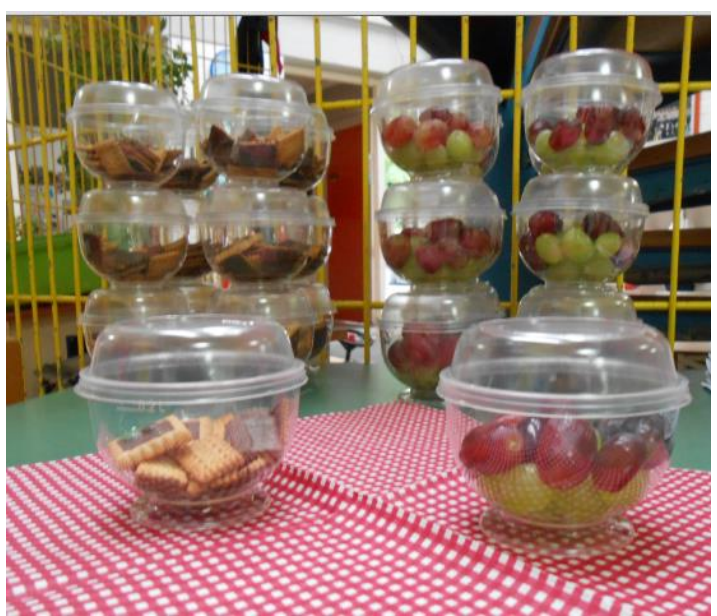

Picture 3: Presentation of food items during experiment 


\section{The Effect of Making a Derived Food Choice}

It is taken care of similar "snacking" conditions of the two food items for the children. Therefore, both containers contain a snack, which is assumed to be commonly-known by kids and generally liked by small children. Both snacks are widely-known, sweet and of small portions. As a result, one container is filled with many, small, single grapes or small chocolate cookies instead of for example one large piece such as a whole chocolate bar. With many small grapes or single chocolate cookies, the snack is assumed to be child friendly as the item fits easily in the mouth of a 2-7 year old. Additionally, the small pieces have the advantage to be portion-able in case the mother does not want to give the whole snack as one to the youngster. Furthermore, the snacks are of comparable sizes as a medium-sized grape is as long as one cookie (ca. $2 \mathrm{~cm}$ ) and a similar amount of pieces are therefore in the containers. Further, it was important that both products are perishable within a similar timeframe. This is of concern, as mothers may otherwise choose a snack, which holds longer or looks "fresher". Consequently, the grapes are assumed to perish within the same time, in which the cookie starts to taste no good anymore and gets soft.

Furthermore, being aware of the fact that one food item might be perceived as containing more sugar, being unhealthier or being of higher value, it was hereby accounted for this instance. Special attention is given to the equivalency of sugar content as it is a reference for healthiness. Also concern is given to price as this is an indicator, of which option might be of higher value in terms of the better deal. By accounting for these aspects, the impact the experimental presentation of the snack might have on the choice of the mother, is aimed to be reduced and eventual biases minimized. So as the table 1 below depicts, the gram amounts the containers are filled with, are chosen on the basis of thorough calculations. Consequently, 100 gram of grapes accord to 41 gram of cookies as they contain almost the same amount of sugar, Fiber, Natrium and are of equal retail prices for the amount given.

Table 1: Comparison of ingredients for the healthy/unhealthy food item

\begin{tabular}{l|cc}
\multicolumn{1}{c}{ Grapes } & Cookies \\
\hline Gramm & $\mathbf{1 0 0}$ & $\mathbf{4 1}$ \\
kcal & 68 & 200,9 \\
Sugar & $\mathbf{1 5 , 4}$ & $\mathbf{1 3 , 1}$ \\
Protein & 0,7 & 3,1 \\
Carb & 15,6 & 26,7 \\
Grease & 0,3 & 8,6 \\
Fiber & $\mathbf{1 , 5}$ & $\mathbf{1 , 2}$ \\
Natrium & $\mathbf{0}$ & $\mathbf{0 , 1}$ \\
Price & $\mathbf{0 , 4 0}$ & $\mathbf{0 , 4 2}$
\end{tabular}


It is therefore ensured, that both snacks hold same characteristics in terms of sugar (healthiness) and value (no "best deal") and that choices are made only due to the preference of the mother and not due to the presentation of the snack.

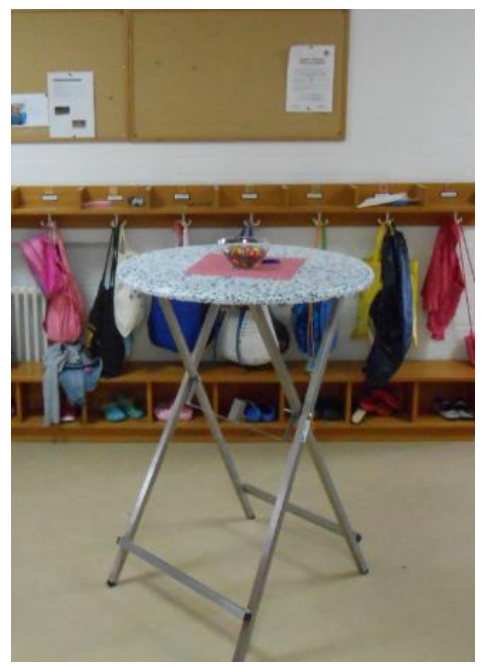

Picture 4: Bar table with M\&M bowl

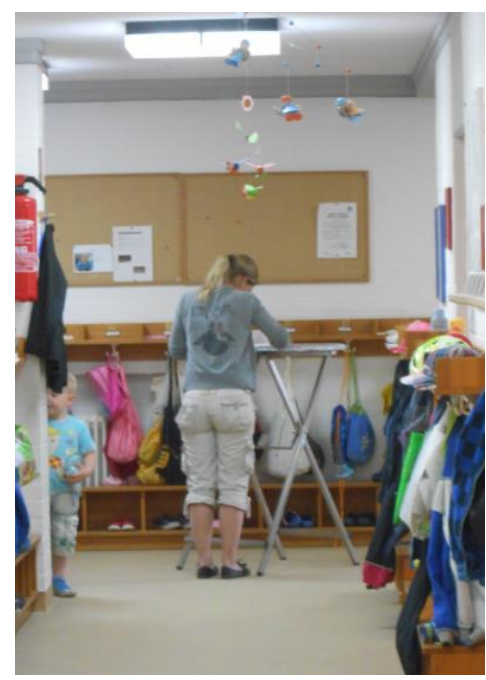

Picture 5: Mother filling in questionnaire at remoted place on bar table

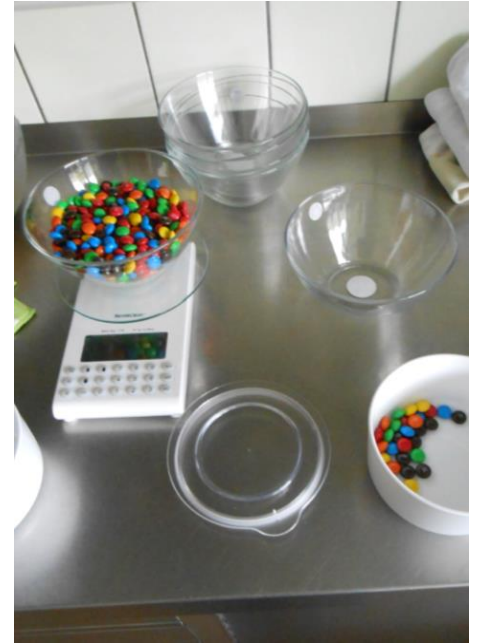

Picture 6: Backstage:

Measuring 500gram

M\&M per bowl

Now, after receiving the item, the participants were each separately guided to a bar table in an empty corner of the hallway where they complete a filler-task questionnaire unrelated to the food topic. In these corners they are not observable and feel being on their own. It was ensured that only one mother fills in the questionnaire per table. During this time, a large bowl of M\&M's (500gr) is provided as snacks on the table. In the research of Kahn and Wansink (2004), it has shown that larger amounts of snack provided, make the personal amount eaten less visible and perceivable and therefore tend to enlarge the amount eaten by the participants. Therefore, a relatively large amount $(500 \mathrm{gr}$ ) is used in order to make the individual amount eaten less perceivable and in turn increase the total amount of M\&M's eaten by the mothers. Additionally, women are told that they can eat if they like in order to address the attention to the snacks. After completing the questionnaire the participants bring the questionnaire to the researcher, are debriefed, thanked and released.

To catalogue the exact amount of M\&M's consumed, pre-test weight (grams) and posttest weight is measure by scale in a separate room out of sight of the participants. 


\section{Descriptive Analysis}

Table 2: Descriptive Statistics

\section{Descriptive Statistics}

\begin{tabular}{lrrrrr}
\hline \hline & N & Minimum & Maximum & Mean & Std. Deviation \\
\hline $\begin{array}{l}\text { Snack amount } \\
\text { consumed by mother }\end{array}$ & 40 & 1 & 37 & 13,00 & 9,517 \\
Age of mother & 40 & 21 & 49 & 32,97 & 5,907 \\
Age of Child & 40 & 2 & 7 & 4,30 & 1,091 \\
Number of Children & 40 & 1 & 4 & 1,90 &, 744 \\
Age of mother by l. & 40 & 17 & 39 & 26,20 & 5,562 \\
child born & & & & & \\
Maximal Weight & 40 & 1 & 187 & 79,93 & 29,669 \\
Weight of Mother & 40 & 48 & 167 & 73,72 & 24,898 \\
Height of Mother & 40 & 156,00 & 180,00 & 169,5000 & 5,11408 \\
Body Mass Index (BMI) & 40 & 19 & 58 & 25,60 & 8,326 \\
Valid N (listwise) & 40 & \multicolumn{7}{c}{} & \\
\hline \hline
\end{tabular}

Taking a look into the descriptive of this study, valid data was gathered from 40 German mothers in the age between 21 and 49 (mean=32,97). The data of 9 mothers was excluded due to eventual biases or non-eating behavior, and 6 mothers denied upfront to take part in the study. The 40 mothers have children in an age between 2 and 7 years (mean $=4,30$ ) and 1,90 children on average. All of the mothers except for one, were of German nationality (see Appendix for Frequency tables). Also, slightly more children in this study are female $(60 \%)$ than male $(40 \%)$.

In general the average woman of this study had her first child in the age of 26,20 years with a range from 17 to 39 years. As Graph 1 depicts, $79 \%$ of the mothers gave birth to their first child up to an age of 30 . Only $21 \%$ gave birth for the first time after turning 30 .

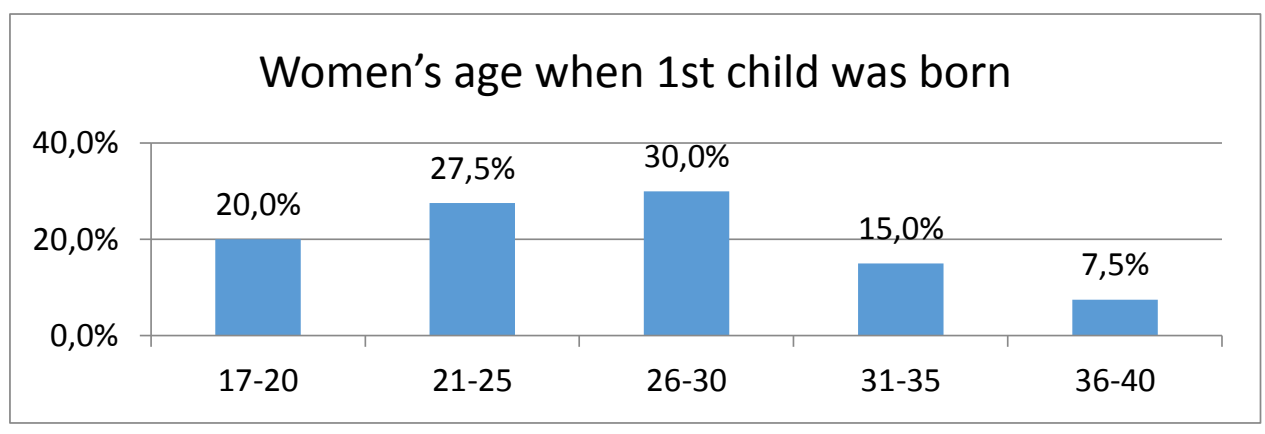

Figure 2: Women's age when $1^{\text {st }}$ child was born 


\section{The Effect of Making a Derived Food Choice}

Regarding the marital status, the majority of $60 \%$ are married, followed by $17,5 \%$ who are divorced, $12,5 \%$ are having a partnership with the father whilst 5,0 \% are single, and $2,5 \%$ are having a new relationship and $2,5 \%$ are even married to a new partner.

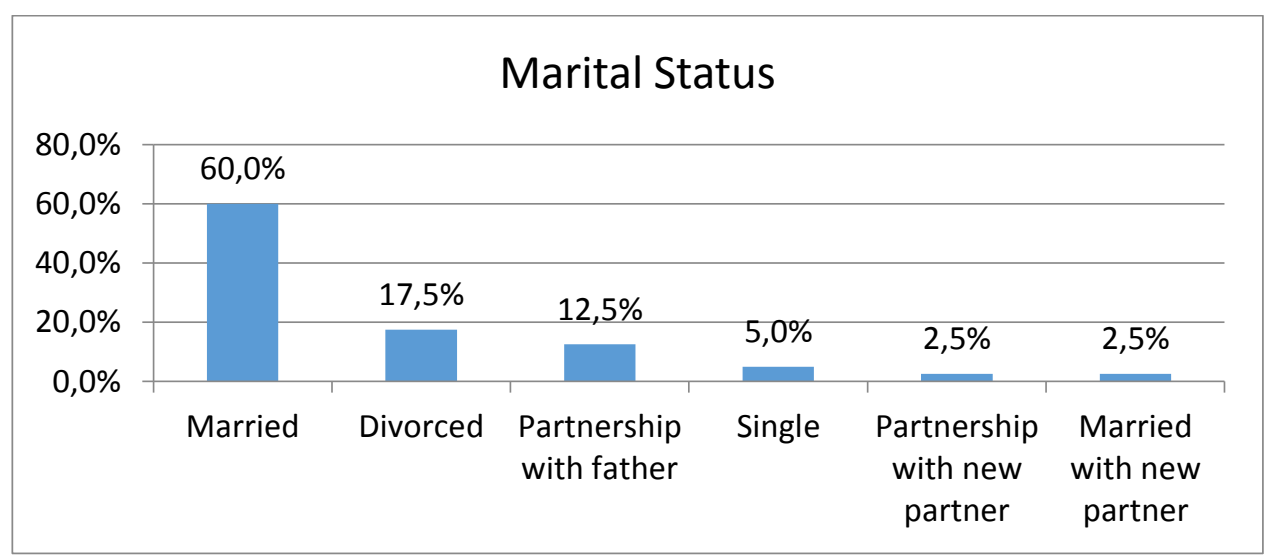

Figure 3: Martial Status

Furthermore, data regarding the status of employment was collected in a threefold manner (Full-time, Part-time, Stay-at-home mom). The majority of the mothers $(62,5 \%)$ work part-time, followed by $22,5 \%$ who stay at home and $15,0 \%$ who still work full-time. Taking a deeper look now into health measures and diet habits, it can be said that of all the mothers in this study 8 persons were on a diet $(20,0 \%)$. The mothers in this study weight between 48 to $167 \mathrm{~kg}$ (mean=73,72kg) and are of a height of $156-180 \mathrm{~cm}$ (mean $=169,5 \mathrm{~cm}$ ). According to a study of the Statistischen Landesamt Rheinlandpfalz in 2009 , women weigh in the state of Rheinland-Pfalz, Germany, on average $83,9 \mathrm{~kg}$ (this study $=73,72 \mathrm{~kg}$ ) and are $165 \mathrm{~cm}$ tall (this study=169,50). So the women of this study seem to be lighter and at the same time slightly taller than the state average. Therefore, it is worth shedding a light on the question of whether women of this study are simply healthier in terms of height/weight constellations, or of whether a matter of punctual obesity or underweight can be observed herein. Consequently, on the basis of the collected data a variable BMI was computed (WeightMother/HeightMother $\left.(m)^{2}\right)$. The descriptive data results show that the range of BMI of this study lies between 19 to 58 with a mean of 25,60 in BMI. According to the Statistischen Landesamt Rheinlandpfalz, a BMI of 18,5-25 is declared as normal weight/height constellation. People below 18,5 are shortweighted and above 25 are overweight. The extreme form of obesity begins at a $\mathrm{BMI}$ of 30 . Therefore, the women of this study are declared on average as slightly overweight as they have a BMI of 25,60 and fall therefore short of the normal weight group of 18,5-25 in BMI. However, this result may be slightly biased due to the fact that two participants are extremely overweight and therefore skew the average upwards 


\section{The Effect of Making a Derived Food Choice}

(156kg and $167 \mathrm{~kg}$ ). Therefore, it is worth taking a second look and to compare the percentage distributions within the four weight groups with the average in Rheinland Pfalz. In this study $0 \%$ of the women are categorized as underweight, $65,0 \%$ are of normal weight, $17,5 \%$ are overweight and $17,5 \%$ are obese. Comparing the results of this study to the data gathered by the Statistischen Landesamt Rheinlandpfalz (2009) for women in the state of Rheinland-Pfalz (where the data of this study was collected) is shown in Figure 4.

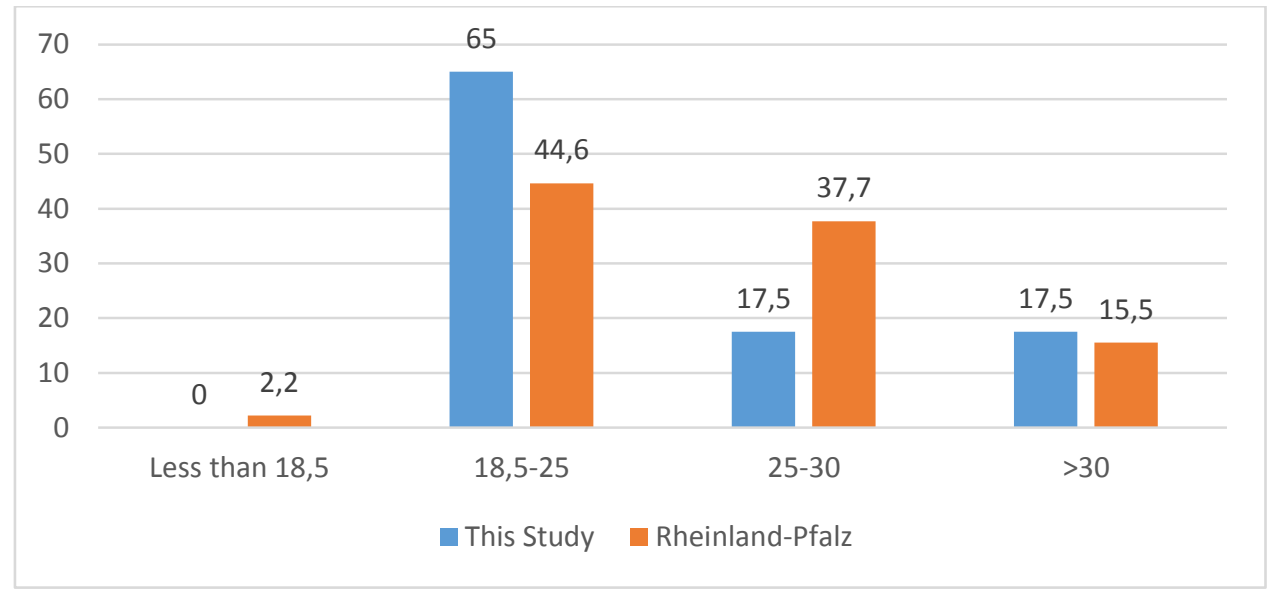

Figure 4: Comparison of percentages of women in BMI groups in Rheinland-Pfalz with this study

Therefore, more women in this study are of normal weight $(+20,4 \%)$ in comparison to average in Rheinland-Pfalz. Less women of this study are overweight $(-20,2 \%)$ and less are underweight $(-2,2 \%)$ but more women in this study are extremely overweight $(+2,0 \%)$ in comparison to overall data of the state. That leads to the conclusion that the sample of women taken from this kindergarten in Rheinlandpfalz has mothers with a healthier BMI constellation in comparison to the state average. These weight descriptives being considered, it is controlled in the following section for eating habits, diets and health indication by means of ANCOVA's controlling for factor, which could effect the result. The question is thereby answered of whether BMI, health, diet, weight and relationships to child and father (Rel1-Rel4) statistically affect the goodness of the statistical results by moderating its' extend or even lowering its' significance.

But first, the descriptives show that of the 40 women $50 \%$ selected grapes (healthy food choice) and $50 \%$ selected cookies (unhealthy food choice) as a present for their children. Therefore, an equal representation of both groups, healthy and unhealthy is given in this study. This equal representation among the groups is an important aspect of the study and hereby successfully met. 


\section{The Effect of Making a Derived Food Choice}

Overall, it can be said that an amount of 520 gram of M\&M were consumed by these 40 women during the session. The pie-chart below indicates that a higher volume (323gram $=62,12 \%$ ) of M\&M was consumed by mothers having chosen the grapes in the beginning of the experiment. This implies that almost two-thirds of the amount of M\&M's were consumed by the participants having performed a healthy food choice for their children in advance. Only $37,88 \%$ (197gram) of the amount eaten this day was consumed by mothers who selected the cookies (unhealthy choice) in the beginning.

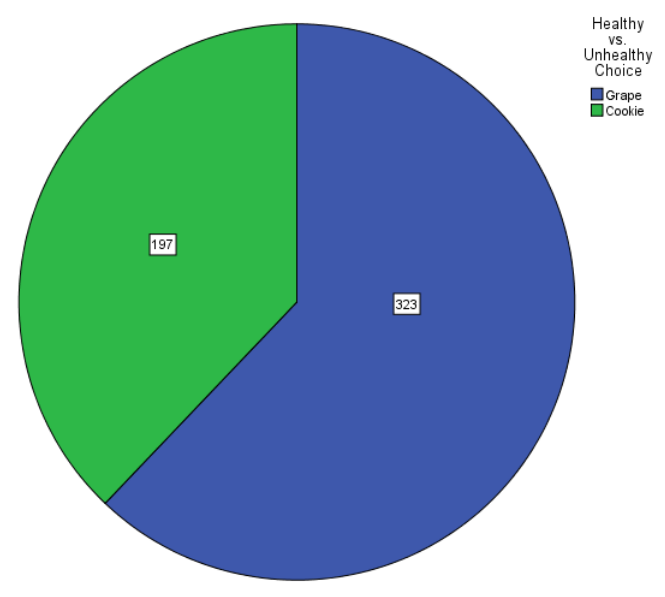

Figure 5: Share of M\&M's eaten per group (healthy[blue]/unhealthy choice[green])

Yet, the above depicted pie chart only indicates the overall amount of M\&M's consumed by mothers during this day per group. However, this study is rather interested in the average snack amount consumed by the mothers individually within the different conditions (healthy vs. unhealthy choice).

Therefore, it is statistically tested in the next section of whether there is indeed a significant difference between the amount consumed and a differently made choice.

\section{Results}

Table 3 gives the statistical results of the performed two-sample t-test.

Table 3: Statistical Output (Significances)

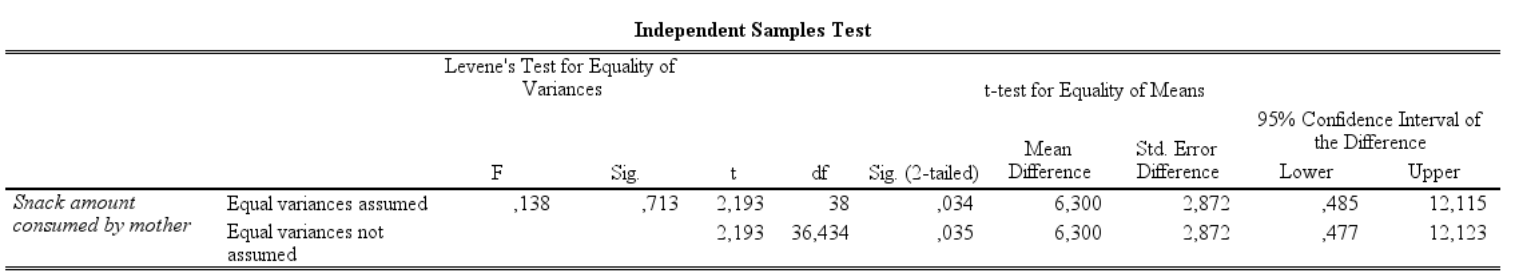




\section{The Effect of Making a Derived Food Choice}

With a significance of $\mathrm{p}=.034$ ( $\mathrm{SE}=2,872 ;\{.485 \mid 12,115\})$, it is can be said that the direction of the results in the performed independent sample t-test is in fact statistically supportable (Table 3).

Therefore, this finding states that there is statistical evidence $(p=.034)$ found for the results of table 4 , which indicates that mothers in the healthy snack group (grapes) ate on average 16,15 gram $\left(S^{\text {grape }}=9.980 ; S^{\text {grape }}=2.232\right)$ of the unhealthy sweets provided, whereas mothers in the unhealthy snack group (cookie) ate only 9,85 gram $\left(\mathrm{SD}^{\text {cookie }}=8,087 ; \mathrm{SE}^{\text {cookie }}=1.808\right)$ of $\mathrm{M} \& \mathrm{M}$ during the experiment.

Table 4: Statistical Output (Means)

Group Statistics

\begin{tabular}{llrrrr}
\hline \hline & $\begin{array}{l}\text { Healthy vs. Unhealthy } \\
\text { Choice }\end{array}$ & N & Mean & Std. Deviation & \multicolumn{1}{c}{ Mean } \\
\hline Snack amount & Grape & 20 & 16,15 & 9,980 & 2,232 \\
consumed by mother & Cookie & 20 & 9,85 & 8,087 & 1,808 \\
\hline \hline
\end{tabular}

This implies that mothers of the unhealthy choice group eat on average one-third less than the ones that have chosen grapes (healthy choice) for their children. This finding goes in line with the predicted trend in the hypothesis. Consequently, significant evidence in line with hypothesis 1 is provided, accepting it on a significance level of $5 \%$ $(p=3,4 \%<5,0 \%)$.

Yet, it is clear that indeed there is an impact of the underlying, derived choice performed by the mother on the mothers' consumption behavior. However, as already said in the last section, it is worth checking for eventual moderations of this relationship. Therefore, ANCOVA's are performed to test for eventual co-variances, interactions and moderations. Especially, it is controlled for BMI, health, diet, weight and relationships to child and father (Rel1-Rel4) as well as demographic measures.

The initial model testing "Group" (healthy vs. unhealthy choice group) on the dependent variable "Snack amount consumed by mother" is indicated below in table 5 . This model being an alternative way of representing the results of a significance of $p=.038$, also gives further insights into additional measures $\left(R^{2}, A d j . R^{2}\right)$ to test the goodness of this reduced model in comparison to extended models. 


\section{The Effect of Making a Derived Food Choice}

Table 5: $R^{2}$ and Adjusted $R^{2}$ for the reduced (original) model

Tests of Between-Subjects Effects

\begin{tabular}{lrrrrr}
\multicolumn{5}{l}{ Dependent Variable: } & Snack amount consumed by mother \\
\hline \hline Type III Sum & & & & & \\
Source & of Squares & \multicolumn{1}{c}{ df } & Mean Square & \multicolumn{1}{c}{ F } & \multicolumn{1}{c}{ Sig. } \\
\hline Corrected Model & $396,900^{2}$ & 1 & 396,900 & 4,811 &, 034 \\
Intercept & 6760,000 & 1 & 6760,000 & 81,937 &, 000 \\
Group & 396,900 & 1 & 396,900 & 4,811 &, 034 \\
Error & 3135,100 & 38 & 82,503 & & \\
Total & 10292,000 & 40 & & & \\
Corrected Total & 3532,000 & 39 & & & \\
\hline \hline
\end{tabular}

a. $\mathrm{R}$ Squared $=, 112$ (Adjusted R Squared $=, 089$ )

In the following, Table 6 indicates the results of sixteen ANCOVA's (see appendix) performed in a condensed and tabular manner, comparing them to a $\mathrm{R}^{2}$ reduced $=.112$, $\mathrm{p}^{\text {reduced }}=.034$ and to an Adjusted $\mathrm{R}^{2}$ reduced $=.089$ of the original model.

Consequently, as depicted in table 6 above, neither the inclusion of the variables DIET $\left(p^{\text {DIET }}=.211, R^{2}=.151\right.$, Adj. $\left.R^{2}=.080\right)$, HEALTH $\left(p^{\text {HEALTH }}=.689, R^{2}=.160\right.$, Adj. $\left.R^{2}=.079\right)$, WeightHIGH ( $p^{\text {WeightHIGH }}=.109, R^{2}=.174$, Adj. $\left.R^{2}=.106\right)$, TimeMealMin $\left(p^{\text {TimeMealMin }}=.884\right.$, $\mathrm{R}^{2}=.113$, Adj. $\mathrm{R}^{2}=.039$ ) nor of the BMI ( $\mathrm{p}^{\mathrm{BMI}}=.134, \mathrm{R}^{2}=.168$, Adj. $\mathrm{R}^{2}=.096$ ) seem to have a significant $(\alpha=.10)$ effect on the model. Therefore, they are not statistical significant for bettering the models' fit ( $R^{2}$ and Adjusted $\left.R^{2}\right)$ even when they increase its' goodness in comparison to the initial, reduced model. Therefore, also variables bettering the models $\mathrm{R}^{2}$ and adjusted $\mathrm{R}^{2}$ are excluded, such as WeightHIGH $\left(\mathrm{R}^{2}{ }^{\text {WeightHIGH }}=.174>.112\right.$, Adj. $\mathrm{R}^{2}$

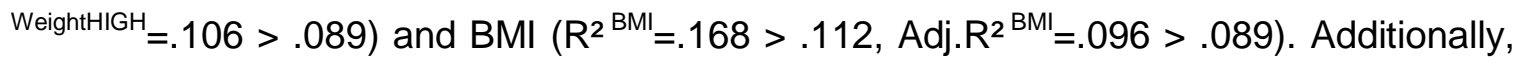
all of these five variables were tested on eventual interaction with the phenomena. However, for all five was not found any significant interaction effect on the $10 \%$ level $\left(\mathrm{p}^{\text {DIET*Group }}=.648, \mathrm{p}^{\text {HEALTH*Group }}=.630, \mathrm{p}^{\text {WeightHIGH*Group }}=.934, \mathrm{p}^{\text {TimeMealMin*Group }}=.978\right.$, $\mathrm{p}^{\mathrm{BM}{ }^{*} \mathrm{Group}}=.688$ ) and above that the significant effect of the overall (indicated as $\mathrm{p}^{\cdots 0}$ ), main model even disappeared $\left(\mathrm{p}^{\text {DIETO }}=.174, \mathrm{p}^{\text {HEALTHO }}=.998, \mathrm{p}^{\text {WeightHIGHO }}=.453\right.$, $\left.\mathrm{p}^{\text {TimeMealMinO }}=.430, \mathrm{p}^{\mathrm{BM} \mathrm{I}^{*} \mathrm{Group}}=.734>.034\right)$. Thus, it is found that nutrition factors such as that participants are currently dieting, or are especially health conscious, or are of high weight already, or have just eaten a meal, or have a normal/overweight BMI, do neither effect nor interact with the amount eaten by the mother. 
The Effect of Making a Derived Food Choice

Table 6: Comparison of different extended models with reduced model

ANCOVA

Dependent Variable: Snack amount consumed

\begin{tabular}{|c|c|c|c|c|c|c|c|}
\hline Moderator & $\mathrm{R}^{2}$ & $\begin{array}{l}\text { Adj } \\
\mathrm{R}^{2}\end{array}$ & $\begin{array}{c}\text { Moderato } \\
r \\
p \text {-value }\end{array}$ & $\begin{array}{c}\text { New } \\
\text { Group } \\
\text { p-value }\end{array}$ & $\begin{array}{c}\text { Interac } \\
\text { tion }\end{array}$ & $\begin{array}{l}\text { Correl } \\
\text { ation }\end{array}$ & $\begin{array}{c}\text { Effect } \\
\text { on Adj. } \\
R^{2}\end{array}$ \\
\hline Group & .112 & .089 & & $.038^{\star \star}$ & & & \\
\hline DIET & .151 & .080 & .211 & .174 & .648 & & - \\
\hline HEALTH & .160 & .079 & .689 & .998 & .630 & & - \\
\hline WeightHIGH & .174 & .106 & .109 & .453 & .934 & & + \\
\hline TimeMealMin & .113 & .039 & .884 & .430 & .978 & & - \\
\hline$B M I$ & .168 & .096 & .134 & .734 & .688 & & + \\
\hline Rel1 & .121 & .074 & .550 & $.035^{* *}$ & & & - \\
\hline Rel2 & .122 & .073 & .342 & $.065^{*}$ & & & - \\
\hline Rel3 & .228 & .185 & $.025^{\star \star}$ & $.023^{* *}$ & & $-.326^{*}$ & $+{ }^{* *}$ \\
\hline Rel4 & .271 & .231 & $.007^{* \star *}$ & $.008^{* * *}$ & & $-.341^{*}$ & $++^{* * *}$ \\
\hline MoAge & .115 & .041 & .839 & .579 & .846 & & -- \\
\hline BirthAge & .118 & .044 & .635 & .650 & .981 & & -- \\
\hline NoChild & .160 & .090 & .938 & $.048^{* *}$ & .171 & & + \\
\hline Gen & .140 & .093 & .283 & $.087^{\star}$ & & & + \\
\hline MarStatus & .115 & .067 & .745 & $.035^{\star \star}$ & & & - \\
\hline ChiAge & .182 & .038 & $.084^{*}$ & $.030^{* *}$ & & +.264 & - \\
\hline$E M$ & & & & & 0.12 & & - \\
\hline
\end{tabular}

Eating

Habit

Relation-

ships

Demo-

graphics

${ }^{*}$ significant on $10 \%$ level ${ }^{* *}$ significant on $5 \%$ level ${ }^{* * *}$ significant on $1 \%$ level

+ bettering the effect - worsening the effect -- heavily worsening the effect (see code book in appendix for full names of variables) 


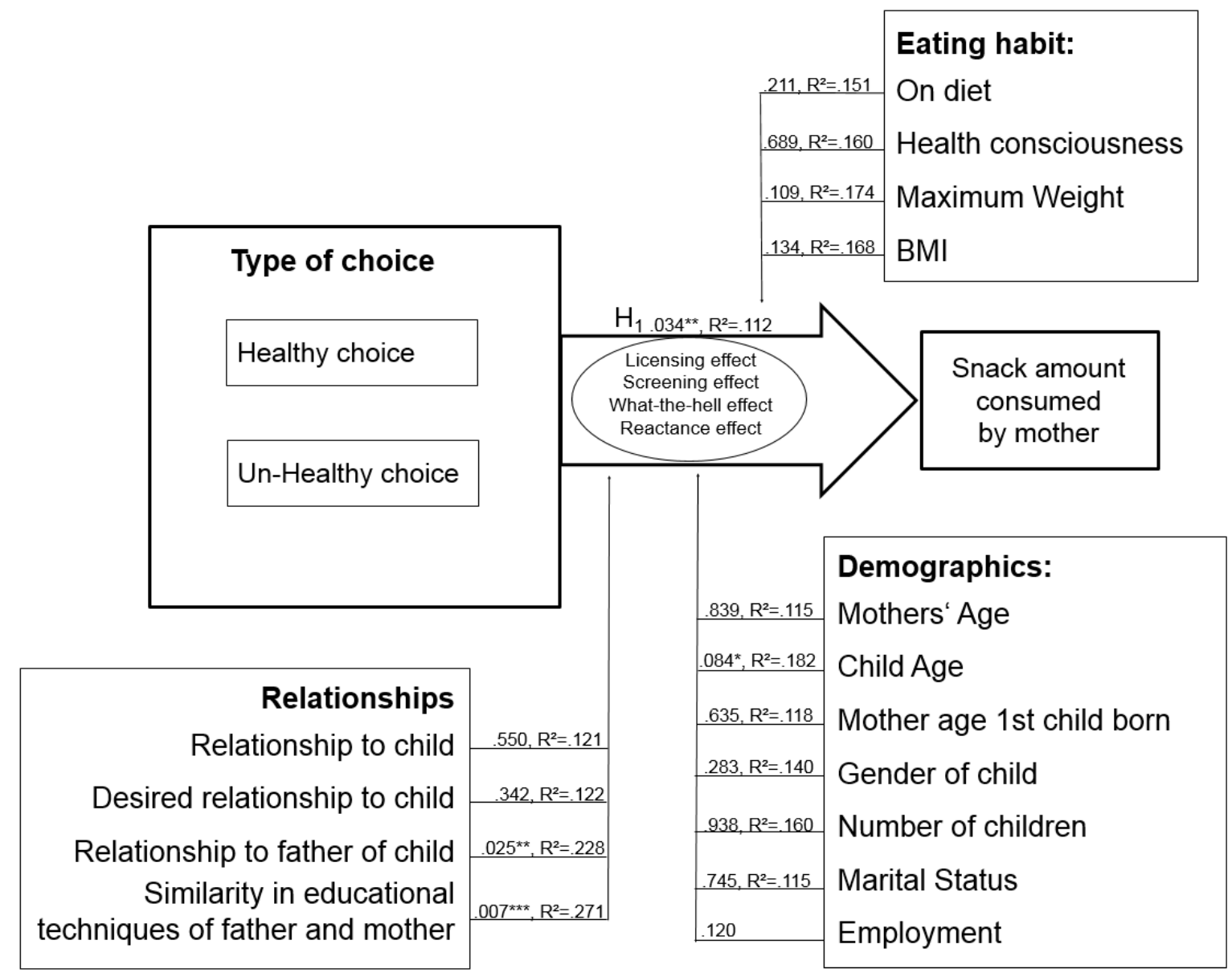

Figure 6: Results of conceptual model

Furthermore, looking into relationship factors, it is found that Rel1 (Relationship motherchild) as well as Rel2 (Desired relationship mother-child) are both insignificant $\left(\mathrm{p}^{\text {Rel1 }}=.550, \mathrm{p}^{\text {Rel2 }}=.342\right)$ in moderating the underlying phenomena and do not better the models explanation capacity (Adj. $R^{2}$ Rel1 $=.074<.089$; Adj. $R^{2}$ Rel2 $=.073<.089$ ). This is found nevertheless that the overall significance of the main model remained significant $\left(\mathrm{p}^{\text {Rel1 }}=.035, \mathrm{p}^{\text {Rel2 }}=.065\right)$, even when increasing the probability of a type 1 error. Thus, the relationship between mother and child does not lead to a greater amount consumed by the mother because the moderator $p$-values of the variables are each insignificant.

However, Rel3 (Relationship mother-father) and Rel4 (Similarity education techniques mother-father) do not only better the models explanation ability $\left(\mathrm{R}^{2}{ }^{\mathrm{Re} 3}=.228>.112\right.$ and Adj. $\mathrm{R}^{2}$ Rel3 $=.185>.089, \mathrm{R}^{2}{ }_{\text {Rel4}}=.271>.112$ and Adj. $\mathrm{R}^{2}{ }^{\mathrm{Rel} 4}=.231>.089$ ), but also are significant on $5 \%$ level $(\alpha=.05)$ and so moderating the underlying phenomena $\left(p^{\text {Rel3 }}=.025\right.$; $\left.\mathrm{p}^{\text {Rel4}}=.007\right)$. Also the main model $(\mathrm{p}=.034)$ becomes more significant when these variables are included $\left(\mathrm{p}^{\text {Rel3O }}=.023 ; \mathrm{p}^{\text {Rel4O }}=.008\right)$. Now that a significant moderation is found, it is tested for the direction of the moderation. Therefore, correlation analysis are performed. 
Table 7: Correlation output for the moderation of the relationship mother-father on snack amount consumed by the mother

\begin{tabular}{llrr}
\multicolumn{4}{c}{ Correlations } \\
\hline \hline & $\begin{array}{c}\text { Snack amount } \\
\text { consumed by } \\
\text { mother }\end{array}$ & Rel3 \\
\hline Snack amount & Pearson Correlation & 1 &,- 326 \\
consumed by mother & Sig. (2-tailed) &, 043 \\
& N & 40 & 39 \\
\hline Rel3 & Pearson Correlation &,- 326 & 1 \\
& Sig. (2-tailed) &, 043 & \\
& N & 39 & 39 \\
\hline \hline
\end{tabular}

Table 8: Correlation output for the moderation of the similarity in educational techniques of mother-father on snack amount consumed by the mother

\begin{tabular}{llrr}
\multicolumn{4}{c}{ Correlations } \\
\hline & \multicolumn{2}{c}{$\begin{array}{c}\text { Snack amount } \\
\text { consumed by } \\
\text { mother }\end{array}$} & Rel4 \\
\hline Snack amount & Pearson Correlation & 1 &,- 338 \\
consumed by mother & Sig. (2-tailed) &, 033 \\
& N & 40 & 40 \\
\hline Rel4 & Pearson Correlation &,- 338 & 1 \\
& Sig. (2-tailed) &, 033 & \\
& N & 40 & 40 \\
\hline \hline
\end{tabular}

The output of the correlation analysis in table 7 indicates that for Rel3 (Relationship mother-father) a negative correlation (-.326*) between the relationship between motherfather and the snack amount consumed by the mother can be detected. This result is significant on a $5 \%$ level. It seems that the better the relationship to the father, the less is eaten of a sweet snack by the mother.

But also for Rel4 (Similarity education techniques mother-father) the correlation test in table 8 shows a significant, negative correlation $\left(-.338^{*}\right)$ between the similarity of the parents educational techniques and the snack amount eaten by the mother. This implies that the more similar the educational techniques of mother and father are, the lower becomes the amount of sweets mothers snack.

Consequently, Rel3 and Rel4 better the model and should be included as moderators in the overall framework.

Now, checking for demographical aspects, which eventually moderate the results, it is found that neither Mothers current age (MoAge) nor the age, in which the mother gave birth to her first child (BirthAge), have a significant moderation effect on the phenomena. No significant $p$-value can be found on an alpha level of $10 \%\left(p^{\text {MoAge }}=.839 ; p^{\text {BirthAge }}=.635\right)$. 


\section{The Effect of Making a Derived Food Choice}

Furthermore, the inclusion of the variables would individually worsen the models $p$-value as well as adjusted $\mathrm{R}^{2}$ in comparison to the reduced model $\left(\mathrm{p}^{\mathrm{MoAgeO}}=.579 ; \mathrm{p}^{\mathrm{BirthAgeO}}=.650\right.$

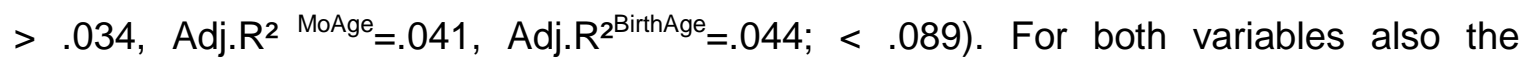
interaction variables MoAge ${ }^{\star}$ Group and BirthAge ${ }^{\star}$ Group were tested, which both turned out to be insignificant on the $10 \%$ level $\left(p^{\text {MoAge Group }}=.846, p^{\text {BirthAge Group }}=.981\right)$. Therefore, mothers' age as well the age first given birth in, are not moderating, interacting with, or bettering the main effect.

Further demographics such as the marital status, the number of children and the gender of the child better the overall explanation capacity of the model by having a higher $R^{2}\left(R^{2}\right.$ MarStatus $=.115, R^{2}$ Nochild $=.160, R^{2}$ Gen $\left.=.140\right)$ than the reduced model $\left(R^{2}\right.$ reduced $\left.=.112\right)$. Also the adjusted $R^{2}$ is higher for number of children and gender of the child when being included in the model (Adj. $\mathrm{R}^{2}$ NoChild $=.090$, Adj. $\mathrm{R}^{2} \mathrm{Gen}=.093$ ) than for the original model $\left(\right.$ Adj. $\mathrm{R}^{2}$ reduced $\left.=.089\right)$. However, for all three measures the $\mathrm{p}$-values for these variables are insignificant $\left(\mathrm{p}^{\text {MarStatus }}=.745, \mathrm{p}^{\text {NoChild }}=.938, \mathrm{p}^{\text {Gen }}=.283\right.$ ) on a $10 \%$ level even when the overall model remains significant $\left(\mathrm{p}^{\text {MarStatusO }}=.035, \mathrm{p}^{\text {NoChildO }}=.048, \mathrm{p}^{\mathrm{GenO}}=.087\right.$ ) with $\alpha=10 \%$. Additionally, for the number of children also the tested interaction effect is not significant ( $\mathrm{p}^{\text {NoChild*Group }}=.171$ ). Consequently, all three (marital status, number of children, gender of the child) do neither moderate nor interact with this model and are therefore excluded.

Table 9: Correlation analysis of Age of Child vs. Snack amount consumed by mother

\section{Correlations}

\begin{tabular}{llrr}
\hline \hline & & $\begin{array}{c}\text { Snack amount } \\
\text { consumed by } \\
\text { mother }\end{array}$ & Age of Child \\
\hline $\begin{array}{l}\text { Snack amount } \\
\text { consumed by mother }\end{array}$ & Pearson Correlation & 1 &, 264 \\
& Sig. (2-tailed) & 40 &, 099 \\
& N &, 264 & 40 \\
\hline Age of Child & Pearson Correlation &, 099 & 1 \\
& Sig. (2-tailed) & 40 & 40 \\
\hline \hline
\end{tabular}

Furthermore, it was assumed that the age of the child (ChiAge) has an effect on the amount eaten by mothers. With the ANCOVA it is found that the inclusion of ChiAge as a variable betters the models explanation capacity $\left(R^{2}{ }^{\text {ChiAge }}=.182>R^{2}{ }^{\text {reduced }}=.112 ;\right.$ Adj. $R^{2}$ ChiAge $^{*}=.138>\mathrm{R}^{2}{ }^{\text {reduced }}=.089$ ) in terms of its $\mathrm{R}^{2}$ and for its adjusted $\mathrm{R}^{2}$. Also, it was found some significant evidence on the $10 \%$ level that the moderator is indeed affecting the results ( $\mathrm{p}^{\text {ChiAge }}=.084$ ) by simultaneously increasing the significance of the overall model 


\section{The Effect of Making a Derived Food Choice}

$\left(\mathrm{p}^{\text {ChiAgeO }}=.030<.034\right)$. Therefore, a follow up correlation analysis (Table 9$)$ is performed and brought the evidence that surprisingly no significant correlation exists $(+.264$ but insignificant) on the $5 \%$ level as the correlation table 9 depicts. Therefore, no effect can be evidenced.

Lastly, the effect of employment (EM) on the amount consumed by mothers is analyzed. It was found no significant evidence $\left(p^{\mathrm{EM}}=.12>\alpha=10 \%\right)$ that this variable is moderating the phenomena. Therefore, a follow up correlation analysis is conducted here. Therefore, of whether women are part-time, full time or stay-at-home moms, does not moderate the amount eaten by the mothers in turn.

\section{Discussion}

This study aimed to find an answer to the research question of how making a food choice for a relevant other (the own child) influences the own (in this case the mothers) consumption behavior. Therefore, it is found significant evidence in line with the expectations that mothers who select a healthy food item for their children in moment 1 , eat afterwards in moment 2 more of an unhealthy snack themselves (support for hypothesis 1). Consequently, the theoretical construct of this paper is supported and the underlying concepts introduced in the beginning are assumed to indeed explain the phenomena. As a result, it can be seen as holding that the chain of thoughts can be explained by the concept of the screening effect, licensing effect, "what the hell" effect and the concept of reactance effect.

Thus, perceived health goal satiation via the attribute screening effect (Chakravarti, Janiszewski \& Ülkümen, 2006) seems to correctly describe that when mothers make a healthy nutrition choice for their child, the attribute "healthy" is intrinsically satiated in the moment after the decision. This in turn leads to having the freedom for themselves of a consumption of an unhealthy snack afterwards as the "healthy" attribute is no longer present. Moreover, the licensing effect (Fishbach \& Dhar, 2005; Khan \& Dhar, 2006) gives a second explanation of the pattern of perceived heath goal satiation in the same direction. Having fulfilled their overall goal of nurturing their families healthy and buying healthy food for the youngsters, mothers give themselves the license for personal, shortterm appetite satisfaction as compensation. The reactance effect (Brehm, 1966) increases the attractiveness of the forbidden snack even more. Thus, conforming to the norm of providing the youngsters with healthy food only, mothers neglect unhealthy and sweet food, making it more interesting for themselves later on. Due to the elimination of this option in the first place, they perceive it as more attractive and therefore fall for the temptation when nobody looks. Lastly, the "what the hell" effect (Polivy \& Herman,1985) 


\section{The Effect of Making a Derived Food Choice}

explains the pattern that when mothers started to eat, they in turn ate higher amounts. That is due to the thinking that if they already acted against their health goal, now it does not matter anymore anyways when they eat the whole bowl.

So, this chain of thoughts seem to correctly elucidate the underlying phenomena leading to the result of this study that mothers who selected a healthy food item for their children in turn eat a higher amount of unhealthy snacks afterwards when compared to mothers selecting a unhealthy food item.

Additionally, the results of the moderation tests show that there is no effect of BMI, health consciousness, being on a diet, actual weight, time lastly eaten and demographic measures on the goodness of the model. This is surprising as one would have assumed that mothers being healthier (better $\mathrm{BMI}$ ), eating less due to a diet or due to having just eaten, or eating more health conscious, would in turn eat lower amounts of M\&M and therefore constrain the result. Yet, it showed that none of the health and eating related habits has a moderating effect on the results.

However, it showed that the relationship of mother and father as well as the similarity between their individual educational techniques, have indeed a moderating effect on the results. This implies that the more satisfied the mother is in the relationship with the father of the child and the more congruent the educational techniques are, the lower is the probability that women will eat sweet snacks. That could be explained by the intrinsic feeling of happiness the women hold. The happier the women with her relationship and the less trouble and disagreement is given regarding the child, the less reasons do women have to add happiness to their life's in form of chocolate and sweets.

\section{Social and managerial Implications}

Now that it is evidenced that the phenomena of making a derived choice for a relevant other person is capable to already pre-fulfill own goals, social and managerial implications result from this conclusion.

Firstly, this finding allows for the interpretation of the consumer behavior in today's society that mothers are able to perceive an artificial goal satiation for themselves resulting from any goal, which they successfully fulfilled in favor of their children. So, this implies that mothers may make use of products and services such as sunscreen or shopping trips, yet receive their personal satisfaction not from protecting themselves with the sunscreen or buying nice clothes for themselves, but rather from ensuring that the child gets not sunburned or that the child finds some new, sweet clothes. This finding goes in line with the quote in the beginning of this paper, which states that the mothers' highest luck is the fact that the child is happy and healthy. Here again it is evidenced, 


\section{The Effect of Making a Derived Food Choice}

how deep the connection between mother and her child in the first years of its life must really be. It appears that they perceive themselves as still being one, sharing not only experiences and memories, but also seem to have a shared account for healthiness and happiness.

Secondly, this study shows again how closely happiness of the mother in her relationship to the father is related to her overall happiness and her consumption behavior. As many studies before this already pictured, consumption is a form of compensation for a lack of happiness in private relationships. This phenomenon is again found as moderating impact, strengthening the underlying effect of higher snack amounts consumed.

Additionally, some managerial implications can be drawn from the findings.

Thus, it is psychologically wise to create print and digital advertisements for grocery products being directed to be seen by adult women but addressing the benefit of these products on the health of the youngsters rather than for the own health. This can be especially interesting for products, which are not necessarily for children but rather general products. By that, a bridge is created spanning the boundary between mothers looking for a healthy nutrition for their children and identifying those products who are capable of that.

Furthermore, these findings give support to the commonly used allocation order of grocery products in supermarkets. Therefore, this study shows that presenting vegetables and fruits first and sweets last on the walk through the supermarket, may increase sales of the sweets. That's because the underlying effects explained in this paper, imply that a goal satisfaction of the "health goal" after the vegetable department is satiated what in turn makes room for unconstrained decisions in the sweet department. Here in the end of the shopping trip, it is now room for freely choosing among the displayed products as all other goals of health are already met. However, having ordered the products the other way around, would lead to a feeling of guilt and too much resistance of falling for the temptation already in the first place because up to now no good decisions have been made, which could license oneself for indulgence. As a result, the order of today's supermarkets also makes sense in the light of this study.

Moreover, this study gives some evidence for the reasoning that in-store personal selling promotions for fruit, vegetables or healthy groceries, lead in turn to a higher sales on sweets as well. Having made a good and healthy decision already by buying the advertised product of the selling stand, women feel free to license themselves for some indulgence shopping in the sweets department as they move on. This is because the goal of purchasing healthy groceries aimed for the family, is met by this, which lifts the constraint of buying only healthy. What still is important is that the decision performed is followed within a short time period by the second "unhealthy" decision. This instance is 


\section{The Effect of Making a Derived Food Choice}

thus given in in-store personal selling promotions. Therefore, marketers of sweets and snacks could benefit from personal selling campaign of "healthy" grocery companies.

Lastly, as the connotation of the licensing effect already indicates, advertisements featuring messages of "treating yourself for being a good mother" are declared to be highly useful on the basis of the results of this study. In-store print advertisement placed repeatingly after the visit of the fruit and vegetable department throughout the store could reinforce and strengthen the drive towards compensating yourself with buying something sweet.

\section{Limitations}

As this study was performed to the best knowledge of the researcher, it was attempted to limit the influence of factors affecting the results as far as this was possible. However, no study is free of unforeseen circumstances and so isn't this one.

Firstly, the actual data collected in the scope of the experiment only basis its conclusions on 40 participants. Significant results are clearly found, however one could argue that a large sample of more than 30 people per condition would be optimal to reach better conclusions from the performed t-test. The $p$-value could even be increased by enlarging the sample size and more powerful results are possible. However, because the data collection takes considerable amount of time as well as participants are hardly to reach in artificial settings of B-labs, this procedure lies beyond the scope of this study and the study allows itself to draw its conclusion already from the given results.

Secondly, the amount consumed may have been negatively influenced by the fact that some mothers had younger children with them in a buggy. They partly were swaying the buggy at some times. This may have replaced some moments where they rather had taken a grip into the bowl of M\&M.

Thirdly, it was sometimes observed that mothers were asking themselves what their child may would prefer. When this was heard, the researcher intervened and pointed out that the choice is to be made from the mother only and in the best interest of the child instead of in favor of the child only. However, other mothers may not have spoken this very same thought out loud and did not make the choice in their own interest but rather in the shortterm interest of the child.

Fourthly, the moment of the last consumption of a full meal may influence the results. To control for the influence this hunger may have on the amount of M\&M eaten, a control variable is included, which recorded the time lately eaten and the actual time. However, this control variable can only partly predict the amount of hunger mothers may hold while filling in the questionnaire. 


\section{The Effect of Making a Derived Food Choice}

Fifthly, the data was measured with a regular cooking scale accounting for full gram amounts. The bowls of M\&M were refilled after each trial to a level of $500 \mathrm{gram}$. However, when measuring the amount eaten by mothers, small amounts or gram variations may have been overlooked and not accounted for in this study.

Sixthly, the amounts eaten by mothers in the rushy situation of picking up their children from the kindergarten are not comparable with amounts consumed in an artificial setting in B-laps given purely experimental conditions with considerable more time. In B-labs participants are absolutely isolated and just concerned with their current task as well as eating. Furthermore, more time is provided and no situation of eventual rush is given. A B-lab session may take up to 1 hour, whereas this study was limited to the individual time participants need to fill in the filler-task questionnaire. This may only have taken between 5-10 minutes, which is a constraint time for undergoing intense snacking behavior. Therefore, in a B-lap setting, mothers may have consumed amounts between 100-200 grams, whereas in this study only very small amounts of 1-37 gram were consumed.

Seventhly, the filler task questionnaire was provided in a paper-based form, which may have negatively influenced the amount consumed due to the fact that the snacking hand was busy holding the pen. This problem was attempted to be limited by asking several open questions, which may need more in depth thinking before writing. This was assumed to compensate partially for the busyness by creating breaks between the writing moments or even moments of perplexity. These moments positively influence the time and amount of snack consumption. However, it is not clear of whether the compensation is sufficient to exclude the negative impact at all.

Lastly, participants are drawn from a better-educated suburb region, which may not represent all variations of mothers within the whole population. However, it is assumed that better-educated mothers are even less affected by the theoretical effects described, as they may know more about healthy nutrition's then persons with lower-education. Therefore, it is predicted that the patterns becoming apparent in problem regions would be even more dramatic in favor of the underlying hypothesis.

\section{Implications for future research}

Having set a first step for climbing the ladder towards the resolution of the question of how derived choices and own nutrition correlate, the study still leaves space for valuable future research.

Thus, it is worth examining of whether the same result or even more dramatic results can be achieved in a less educated district. As the district of the sample population is indicated as rather well-educated, future research could focus on the comparing the 


\section{The Effect of Making a Derived Food Choice}

extent of the effect by featuring communities with different educational backgrounds or persons of different income levels. This would test the moderation of wealth on healthy nutrition and answer the question of whether financially healthier people also naturally make healthier nutrition choices and therefore are less affected by temptations. Thus, low-income sectors could be more heavily influenced by the reactance to a forbidden treat and create more dramatic results in consumption of an unhealthy snack by the mother.

Moreover, the scope of the research could be extended when incorporating the different magnitudes of the effect across different nations. So, as Germany is a country with rather freshly-cooked eating habits, the US may rather focus on more pre-assembled food what in turn could have a strengthening effect of the licensing effect or the reactance effect, which increases the attractiveness of the forbidden and makes it harder for mothers to resist (Fishbach \& Dhar, 2005, Brehm, 1966). This is assumed due to the fact that people already holding the intrinsic tendency to eat on a regular basis less healthy food, are in turn expected to also indulge more easily and to eat more of an unhealthy snack when imposed to this temptation.

Additionally, future research may take a look into the dimensions of the effect when children are older and therefore less dependent on mothers' choice decisions. In the moment when the mothers' burden of making derived choices for their youngsters lightens as they grow up, does that in turn weaken the effect of the phenomena, which let mothers to eat more of unhealthy food due to her good family decisions? So, one would expect that when a mother is no longer making derived choices for her children on a regular basis, also the felt compensation for these good decisions is not given anymore. This in turn could lead to a die-out effect of the phenomena tested in this study as kids become more independent. Consequently, mothers' nutrition should be less affected by her child's nutrition when children grow older.

In addition, this study only focuses on decisions made for a relevant other (the own child). However, it is worth comparing the results of this study in a broader scope with comparable data drawn from experiments with relevant (own child) as well as less relevant persons (other children). Is it correct to assume that the persons' relevance is the key factor in creating the underlying effect of higher consumption of the mother? This expectation is built on the assumption that a feeling of treating yourself as compensation for a good decision is stronger when the person is of importance to you. In this case a feeling of treating yourself for a good deed appears, which leads you to reward yourself with for instance sweets. However, if the person is of no relevance, no considerable feeling of being pleased with yourself should appear as it is of no particular relevance to you that something especially good happens to this person. So, in turn 


\section{The Effect of Making a Derived Food Choice}

compensative eating behavior should be stronger if the decisions you made are performed for relevant instead of less relevant persons.

Moreover, the phenomena is only observed and proved in this study for a female sample population. However, it would be interesting to shed a light on a sample of a population of fathers. TED talkers such as Brooks (2011) already broached the issue that men are less social than women and therefore less likely undergo in this kind of social benefitting behavior in form of making good derived decisions. Consequently, men seem to be less affected by the feeling of having done something good as it seems to be of less relevance to them to be a particular social person. In turn that would lead men to having less reason to compensate themselves with sweets as they do not perceive it as that relevant nor rewarding to be a good or caring person. Here, the question arises of whether men have the same licensing mechanisms in place as women do. These licensing mechanisms (Fishbach \& Dhar, 2005) are responsible for this self-treating behavior in consequence of a good deed and have to be apparent for the phenomena becoming present. One expectation is that men perform only a weaker form of licensing behavior what would explain that they have a lower tendency of rewarding themselves with sweets for social behavior even when its benefitting the own child. Therefore, the fact that men are generally less caring and eventually less affected by compensating behavior, show that it is worth shedding a light on the differences of the effect for mothers and fathers.

Also, marketers might find the question interesting of whether the effect of goal satiation due to a healthy and derived decision for the own child is also artificially creatable by print, TV and digital advertisements. Therefore, is it possible to create a situation where mothers perform a healthy decision at home due to a seen advertisement and in turn hold the intrinsic goal satiation up to the point of the next grocery shopping trip? Or is it rather the fact that it is important to perform the decision by yourself on a real rather than hypothetical item such as during an in-store personal selling campaign? Research of Shiv and Fredorikhin (1999) showed that certain effects only occur when the trigger is real instead of presented in form of a picture or visual ad (hypothetical). Therefore, it could be that the goal satiation effect found in this study is only applicable in in-store advertising activities (personal selling's) and not effective for TV ads. However, this question is worth to be considered in future research.

Lastly, building upon the last mentioned point, research could shed a light on the question of whether an increasing time gap between a performed, derived decision and the moment of the own consumption, leads the effect cease to exist. Thus, as we see supermarkets becoming bigger, the time gap between the healthy decision (vegetable department) and the own unhealthy snacking behavior (sweet department) extents. In 


\section{The Effect of Making a Derived Food Choice}

result, the expectation is that the longer time gap, the more is the strength of a satiated health goal weakened. This could lead to a decrease or even vanish of the perception that attribute "health" is still satiated when arriving at the sweet department and therefore cease the licensing effect on the person to exist (Chakravarti, et al., 2006, Fishbach \& Dhar, 2005).

\section{Conclusion}

In summary, the aim of this study was to clarify the question of how making a derived food choice for a relevant other influences a mothers own consumption behavior. The study was triggered by the paradoxical observation that mothers feel to live unhealthier since they have children nevertheless that they buy now more healthy groceries and are more conscious about health than before. It was managed to shed a light on this problem and to clearly evidence that this phenomena in fact seems to be in place and is not only a matter of perception. Therefore, is was found that mothers who perform a derived choice of a healthy food item for their children, feel themselves free to eat more of unhealthy products afterwards as a consequence of their family benefitting behavior. Having acted in favor of the goal of nurturing the family healthy, the burden to further reinforce this goal for the own person lightens and provides the freedom for indulgence. Finding this result in line with the expectations, the study reveals a second interesting phenomena. It figured that the consumption behavior of mothers is strongly negatively moderated by the perceived happiness in the relationship with the father and the compatibility of both partners' educational techniques. Thus, the happier a mother seems to be with her private life and the less disagreement with the father regarding the education of the child exists, the less is the tendency of the mother to indulge in eating sweets.

This leads to the general conclusion that the nutrition of mothers is closely affected by the derived choices performed for her children and that she is willing with good grace to put herself worse off in order to give good care to her youngsters. And that men, in the past and to the present day, have a strong impact on mothers emotional stability and happiness and therefore, apparently also on her physical health. Women are growing more and more independent and stronger nowadays, but they will never lose their natural drive of caring for the own child with all their heart and never stop being distracted in their self-consciousness by the perplexing species men. 


\section{Questionnaire}

\section{Maastricht University}

Dear participant !

Upfront already many thanks for your participation in this study on mother-child relationships by the University of Maastricht. In the following you find questions regarding your relationship to your child, its education and your own nutrition. Please respond honestly and to your best knowledge. Your data will be treated confidentially and anonym.

Age

Child Age

Childs gender

Nationality

Number of children born

Delivery Age of first child

Employment

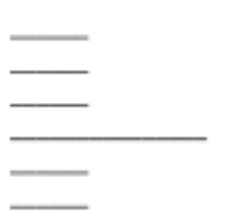

o full-time ( $<6 h /$ day)

\author{
Marital status \\ o married \\ o divorced \\ o partnership with the father \\ o partnership with new partner \\ o single \\ o widow
}

o part-time

o stay-at-home mom

1 Which of the following constellations depicts the relationship of you and your child?
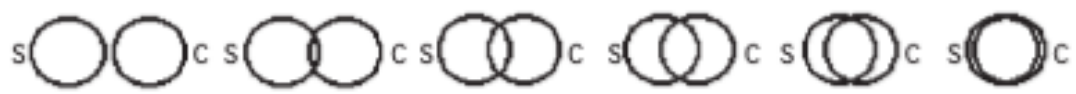

2 Please indicate how you would wish the relationship between you and your child would be.
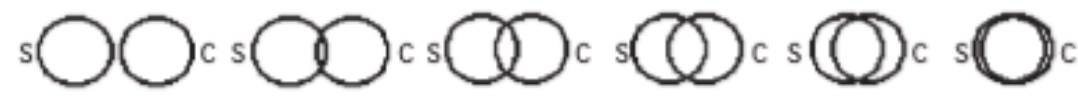

3 Which of the following constellations depicts the relationship of you and the father of your child?<smiles>C1CCC2CCSCCC2CC1</smiles><smiles>[CH]1CCC23CCCCC2CC1C3</smiles><smiles>C1CCC2CCCCC(C1)C2</smiles><smiles>[18OH]</smiles><smiles>CC1CC2CCCC(C1)C2</smiles><smiles>CCCCCCCCSS</smiles>

4 Which of the following constellations depicts the similarity of your and the fathers understanding of educating your child?<smiles></smiles><smiles>CSCCC1CCCCCC1</smiles><smiles>CSCCC12CCCCCC(CC1)C2CS</smiles>
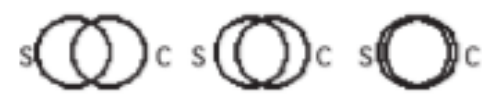

5 To whom do you perceive has your child a closer relationship?

6 is your child a mom's kid or a dad's kid?

7 Who stayed at home in the first months of your childs life?

8 Who is taking the child to bed?

9 Who is preparing the meals for the child?

10 Who cares most about childs healthy diet?

11 Who is full-time working in the family?

12 Whom does your child resemble more in terms of character?

13 Who is spending more time actively playing with the child?

14 Who does the grocery shopping?

$\begin{array}{cccc}\text { Mother } & \text { Father } & \text { Neither } & \text { Both } \\ 0 & 0 & 0 & 0 \\ 0 & 0 & 0 & 0 \\ 0 & 0 & 0 & 0 \\ 0 & 0 & 0 & 0 \\ 0 & 0 & 0 & 0 \\ 0 & 0 & 0 & 0 \\ 0 & 0 & 0 & 0 \\ 0 & 0 & 0 & 0 \\ 0 & 0 & 0 & 0 \\ 0 & 0 & 0 & 0\end{array}$




\section{The Effect of Making a Derived Food Choice}

15 Please list which values are especially important to you to be delivered to your child.

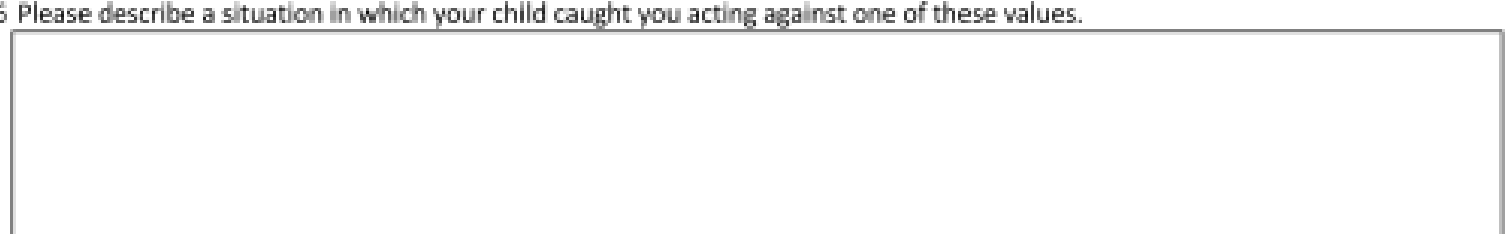

17 How did you handle this situation?

18 Are you satisfied how you handled the situation? What would you do differently today?

19 Please describe 2 differences in the way you and the father are educating the child.

20 What is the most common reason of conflict with your child.

21 What differentiates your child from other children?

22 What are your children strenghts and what are its weaknesses?

23 Do you have special concerns about the nutrition of your child? If yes, which? 


\section{The Effect of Making a Derived Food Choice}

\section{Questions regarding your own nutrition}

24 Are you currently dieting?

25 How often are you generally dieting?

$\begin{array}{cll}\text { O yes } & \text { o no } \\ \text { Never Rarely Sometimes Usually Always }\end{array}$

Are you feeling guilt when you have eaten

27 Do you find yourself eating less in public and more in

Never

Rarely

Usually

Always

27 private?

28 Do you spend too much time thinking of what you

eat?

$\circ$

0

$\circ \quad 0$

o

o

0

29 How conscious are you of what you eat?

Not at all

A bit

Medium

Very much

Would a weight gain of $2,5 \mathrm{~kg}$ affect your way of living?

30 Lebensweise beeinflussen?

o

$\circ$

o

0

o

31 How much is your weight flucturating per week?

$0-0.5$

$0.6-1$

1.1-1.5

$1.5-2.5$

$>2.5$

What was your maximum weight gain in kilos in one

32 week?

D

o

$\circ$

0

o

0

What was your maximum weight loss in one month? 33 (without illnesses)

34 What was your maximum welght to date?

35 How many kilos is that amount above your desired weight?

36 How often do you scale yourself?

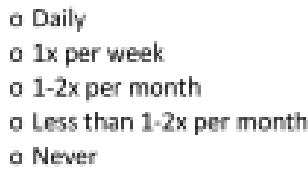

Your weight

Your height

Weight of child

Height of child

37 When did you have your last meal today (breakfast, lunch)?

Please make sure that all questions are answered

Thanks for your time, effort and participation! 
The Effect of Making a Derived Food Choice 


\section{The Effect of Making a Derived Food Choice}

\section{Code Book}

\begin{tabular}{|c|c|c|c|}
\hline Vaviable & Lable & Code & Measure \\
\hline Partic ipant & Participant & None & Scale \\
\hline Group & Healthy vs. Unhea thy Choice & $\{0$, Grape, 1, Cookie $\}$ & Nominal \\
\hline Conswn & Snack amount consumed by mother & None & Scale \\
\hline LocalTure & Test Time & None & Scale \\
\hline Matge & Age of Mother & None & Scale \\
\hline Chisge & Age of Child & None & Scale \\
\hline Gen & Gender of Child & $\{0$ Female, $1 ;$ Male $\}$ & Nominal \\
\hline Nat & Nationality & $\{0$, German, 1 , Other $\}$ & Nominal \\
\hline Nochild & Numer of Children & None & Scale \\
\hline BirthAge & Age of mother by 1 . child bom & None & Scale \\
\hline Marstatus & Marital Status & $\begin{array}{l}\text { \{1, Maried, } 2 \text {, divorced, } 3 \text {, partnered with fa ther of child, } \\
4 \text {, partnered with new partner, } 5 \text {, single, } 6 \text { widow, } \\
7 \text {, manried with new partner }\}\end{array}$ & Ordinal \\
\hline$E M$ & Employment & $\{1$, full-time (>6h), 2, part-time, 3, Stay-at-home mom\} & Ordinal \\
\hline Rell & Relationship Mother and Child & None & Scale \\
\hline $\operatorname{Rel2}$ & Desired re la tionship Mother and Child & None & Scale \\
\hline Rel3 & Rela tionship Mother and Father & None & Scale \\
\hline $\operatorname{Re} 14$ & $\begin{array}{l}\text { Similarity parenting techriques } \\
\text { of mother and father }\end{array}$ & None & Scale \\
\hline$D I E T$ & Dieting & $\{0$, Yes, 1, no $\}$ & Nominal \\
\hline FreDIET & Frequency of dieting & $\{1$, Never, 2, Rarely, 3, Sometimes, 4,Usually, 5, Always $\}$ & Ordinal \\
\hline Guilt & Eating guilt & $\{1$, Never, 2, Rarely, 3, Usuatly, 4, A ways $\}$ & Ordinal \\
\hline ComLess & Hidden Community Eating & $\{1$, Never, 2 , Rarely, 3 , Usually, 4 , Aways $\}$ & Ordinal \\
\hline EatThivk & Thinking a bout eating & $\{1$, Never, 2 , Rarely, 3, Uswatly, 4, Aways $\}$ & Ordinal \\
\hline EarConsci & Conscientioumess of eating & $\{1$, Not at all, 2, A bit, 3, Medium, 4 , Very much $\}$ & Ordinal \\
\hline Lifestyle2.5 & Lifestyle stability & $\{1$, Not at alt, 2, A bit, 3, Medium, 4 , Very much $\}$ & Ordinal \\
\hline he ightFauc & Weeekly weight fluc tura tion & $\{1,0-0.5,2,0.6-1,3,1.1-1.5,4,1.5-2.5,5,>2.5\}$ & Ordinal \\
\hline MaxGainWeek & Maximal weeldy gain & $\{1,0-0.5,2,0.6-1,3,1.1-1.5,4,1.5-2.5,5,>2.5\}$ & Ordinal \\
\hline Max LossMonth & Maximal monthly loss & $\{1,0-2.0,2,2.5-4.5,3,5.0-7.0,4,7.5-10,5,>10\}$ & Ordinal \\
\hline WE ightHIGH & Maximal Weight & None & Scale \\
\hline Desire & Above desired weight & $\{1,0-0.5,2,0.6-2.5,3,2.6-5.0,4,5.1-10,5,>10\}$ & Ordinal \\
\hline Scaling & Frequency of weighting & $\begin{array}{l}\{1, \text { Every day, } 2,1 \times \text { per week, } 3,1-2 x \text { per week, } \\
4,1 \text { ess than } 1-2 x \text { per week, } 5 \text {, never }\}\end{array}$ & Ordinal \\
\hline Wé ight:M & Weight of mother & None & Scale \\
\hline HeightM & Height of mother & None & Scale \\
\hline We ightC & Weight of child & None & Scale \\
\hline HeightC & Height of child & None & Scale \\
\hline EarTone & Time lastely eaten & None & Scale \\
\hline BMI & Body Mass Index & None & Scale \\
\hline BMIGroup & BMII Group & $\{1$, Underwe ight, 2, Norma1, 3, Overweight, 4, Obese $\}$ & Ordinal \\
\hline AgeMoGroup & Age Group Mother & {$[1,18-20,2,21-25,3,26-30,4,31-35,5,36-40,6,41-45,7,46-50\}$} & Nominal \\
\hline$H E A L T H$ & Health consciousnes & None & Scale \\
\hline ToneMealMin & Time since last meal (min) & None & Scale \\
\hline
\end{tabular}


The Effect of Making a Derived Food Choice

\section{Frequency Tables}

\begin{tabular}{llrrrr}
\multicolumn{6}{c}{ Nationality } \\
\hline \hline \\
\hline Valid & Grequency & Percent & Valid Percent & $\begin{array}{c}\text { Cumulative } \\
\text { Percent }\end{array}$ \\
& Other & 1 & 97,5 & 97,5 & 97,5 \\
& Total & 40 & 100,0 & 2,5 & 100,0 \\
\hline \hline
\end{tabular}

\section{Gender of Child}

\begin{tabular}{llrrrr}
\hline \hline & & & & Cumulative \\
Valid & Fremale & 24 & 60,0 & 60,0 & 60,0 \\
& Male & 16 & 40,0 & 40,0 & 100,0 \\
& Total & 40 & 100,0 & 100,0 & \\
\hline \hline
\end{tabular}

\section{Marital Status}

\begin{tabular}{|c|c|c|c|c|c|}
\hline & & Frequency & Percent & Valid Percent & $\begin{array}{l}\text { Cumulative } \\
\text { Percent }\end{array}$ \\
\hline \multirow[t]{7}{*}{ Valid } & Married & 24 & 60,0 & 60,0 & 60,0 \\
\hline & Divorced & 7 & 17,5 & 17,5 & 77,5 \\
\hline & $\begin{array}{l}\text { Partnership with } \\
\text { father }\end{array}$ & 5 & 12,5 & 12,5 & 90,0 \\
\hline & $\begin{array}{l}\text { Partnership with new } \\
\text { partner }\end{array}$ & 1 & 2,5 & 2,5 & 92,5 \\
\hline & SIngle & 2 & 5,0 & 5,0 & 97,5 \\
\hline & $\begin{array}{l}\text { Married with new } \\
\text { partner }\end{array}$ & 1 & 2,5 & 2,5 & 100,0 \\
\hline & Total & 40 & 100,0 & 100,0 & \\
\hline
\end{tabular}

Employment

\begin{tabular}{llrrrr}
\hline \hline & & & & Cumulative \\
& & Frequency & Percent & Valid Percent & Percent \\
\hline Valid & Full-time & 6 & 15,0 & 15,0 & 15,0 \\
& Part-time & 25 & 62,5 & 62,5 & 77,5 \\
& Stay at home mom & 9 & 22,5 & 22,5 & 100,0 \\
Total & 40 & 100,0 & 100,0 & \\
\hline \hline
\end{tabular}


The Effect of Making a Derived Food Choice

Dieting

\begin{tabular}{llrrrr}
\hline \hline & & & & Cumulative \\
& & Frequency & Percent & Valid Percent & Percent \\
\hline Valid & Yes & 8 & 20,0 & 20,0 & 20,0 \\
& No & 32 & 80,0 & 80,0 & 100,0 \\
& Total & 40 & 100,0 & 100,0 & \\
\hline \hline
\end{tabular}

BMI Group

\begin{tabular}{llrrrr}
\hline \hline & & & & Cumulative \\
& & Frequency & Percent & Valid Percent & Percent \\
\hline Valid & Normal Weight & 26 & 65,0 & 65,0 & 65,0 \\
& Overweight & 7 & 17,5 & 17,5 & 82,5 \\
& Obese & 7 & 17,5 & 17,5 & 100,0 \\
Total & 40 & 100,0 & 100,0 & \\
\hline \hline
\end{tabular}

Age Group Mother

\begin{tabular}{lrrrrr}
\hline \hline & & & & Cumulative \\
Valid & $21-25$ & 4 & 10,0 & 10,0 & 10,0 \\
& $26-30$ & 10 & 25,0 & 25,0 & 35,0 \\
& $31-35$ & 12 & 30,0 & 30,0 & 65,0 \\
& $36-40$ & 10 & 25,0 & 25,0 & 90,0 \\
& $41-45$ & 3 & 7,5 & 7,5 & 97,5 \\
& $46-50$ & 1 & 2,5 & 2,5 & 100,0 \\
& Total & 40 & 100,0 & 100,0 & \\
\hline \hline
\end{tabular}


The Effect of Making a Derived Food Choice

\section{ANCOVA's}

\section{Tests of Between-Subjects Effects}

Dependent Variable: Snack amount consumed by mother

\begin{tabular}{lrrrrr}
\hline Source & $\begin{array}{c}\text { Type II Sum } \\
\text { of Squares }\end{array}$ & df & Mean Square & \multicolumn{1}{c}{ F } & Sig. \\
\hline Corrected Model & $532,508^{2}$ & 3 & 177,503 & 2,130 &, 113 \\
Intercept & 450,667 & 1 & 450,667 & 5,409 &, 026 \\
Group * DIET & 17,681 & 1 & 17,681 &, 212 &, 648 \\
Group & 160,167 & 1 & 160,167 & 1,922 &, 174 \\
DIET & 135,368 & 1 & 135,368 & 1,625 &, 211 \\
Error & 2999,492 & 36 & 83,319 & & \\
Total & 10292,000 & 40 & & & \\
Corrected Total & 3532,000 & 39 & & & \\
\hline \hline
\end{tabular}

a. $\mathrm{R}$ Squared $=, 151$ (Adjusted R Squared $=, 080$ )

\section{Tests of Between-Subjects Effects}

Dependent Variable: Snack amount consumed by mother

\begin{tabular}{lrrrrr}
\hline Source & $\begin{array}{c}\text { Type II Sum } \\
\text { of Squares }\end{array}$ & df & Mean Square & \multicolumn{1}{c}{ F } & \multicolumn{1}{c}{ Sig. } \\
\hline Corrected Model & $416,776^{2}$ & 3 & 138,925 & 1,605 &, 205 \\
Intercept & 155,737 & 1 & 155,737 & 1,800 &, 188 \\
Group & 18,101 & 1 & 18,101 &, 209 &, 650 \\
Group * BirthAge &, 048 & 1 &, 048 &, 001 &, 981 \\
BirthAge & 19,875 & 1 & 19,875 &, 230 &, 635 \\
Error & 3115,224 & 36 & 86,534 & & \\
Total & 10292,000 & 40 & & & \\
Corrected Total & 3532,000 & 39 & & & \\
\hline \hline
\end{tabular}

a. R Squared $=, 118$ (Adjusted R Squared $=, 044$ ) 


\section{Tests of Between-Subjects Effects}

Dependent Variable: Snack amount consumed by mother

\begin{tabular}{lrrrrr}
\hline \hline Source & $\begin{array}{c}\text { Type III Sum } \\
\text { of Squares }\end{array}$ & df & Mean Square & \multicolumn{1}{c}{ F } & \multicolumn{1}{c}{ Sig. } \\
\hline Corrected Model & $427,437^{2}$ & 2 & 213,718 & 2,547 &, 092 \\
Intercept & 70,038 & 1 & 70,038 &, 835 &, 367 \\
Group & 403,375 & 1 & 403,375 & 4,807 &, 035 \\
Rell & 30,537 & 1 & 30,537 &, 364 &, 550 \\
Error & 3104,563 & 37 & 83,907 & & \\
Total & 10292,000 & 40 & & & \\
Corrected Total & 3532,000 & 39 & & & \\
\hline \hline
\end{tabular}

a. $\mathrm{R}$ Squared $=, 121$ (Adjusted R Squared $=, 074)$

\section{Tests of Between-Subjects Effects}

Dependent Variable: Snack amount consumed by mother

\begin{tabular}{lrrrrr}
\hline Source & $\begin{array}{c}\text { Type III Sum } \\
\text { of Squares }\end{array}$ & df & Mean Square & \multicolumn{1}{c}{ F } & \multicolumn{1}{c}{ Sig. } \\
\hline Corrected Model & $414,639^{2}$ & 2 & 207,320 & 2,493 &, 097 \\
Intercept & 10,033 & 1 & 10,033 &, 121 &, 730 \\
Group & 301,480 & 1 & 301,480 & 3,626 &, 065 \\
Rel2 & 76,976 & 1 & 76,976 &, 926 &, 342 \\
Error & 2993,258 & 36 & 83,146 & & \\
Total & 10288,000 & 39 & & & \\
Corrected Total & 3407,897 & 38 & & & \\
\hline \hline
\end{tabular}

a. $\mathrm{R}$ Squared $=, 122$ (Adjusted R Squared $=, 073$ )

\section{Tests of Between-Subjects Effects}

Dependent Variable: Snack amount consumed by mother

\begin{tabular}{lrrrrr}
\hline \hline Source & $\begin{array}{c}\text { Type II Sum } \\
\text { of Squares }\end{array}$ & df & Mean Square & \multicolumn{1}{c}{ F } & \multicolumn{1}{c}{ Sig. } \\
\hline Corrected Model & $801,949^{2}$ & 2 & 400,975 & 5,305 &, 010 \\
Intercept & 2288,644 & 1 & 2288,644 & 30,282 &, 000 \\
Group & 427,246 & 1 & 427,246 & 5,653 &, 023 \\
Rel3 & 414,256 & 1 & 414,256 & 5,481 &, 025 \\
Error & 2720,820 & 36 & 75,578 & & \\
Total & 10036,000 & 39 & & & \\
Corrected Total & 3522,769 & 38 & & & \\
\hline \hline
\end{tabular}

a. $\mathrm{R}$ Squared $=, 228$ (Adjusted R Squared $=, 185)$ 
The Effect of Making a Derived Food Choice

\section{Correlations}

\begin{tabular}{llrr}
\hline \hline & & $\begin{array}{c}\text { Snack amount } \\
\text { consumed by } \\
\text { mother }\end{array}$ & \multicolumn{1}{c}{ Rel3 } \\
\hline Snack amount & Pearson Correlation & 1 &,- 326 \\
consumed by mother & Sig. (2-tailed) & 40 &, 043 \\
& N & 39 \\
\hline Rel3 & Pearson Correlation &,- 326 & 1 \\
& Sig. (2-tailed) &, 043 & \\
& N & 39 & 39 \\
\hline \hline
\end{tabular}

*. Correlation is significant at the 0.05 level (2-tailed).

\section{Tests of Between-Subjects Effects}

Dependent Variable: Snack amount consumed by mother

\begin{tabular}{lcrrrr}
\hline \hline Source & $\begin{array}{c}\text { Type III Sum } \\
\text { of Squares }\end{array}$ & df & Mean Square & \multicolumn{1}{c}{ F } & \multicolumn{1}{c}{ Sig. } \\
\hline Corrected Model & $956,078^{2}$ & 2 & 478,039 & 6,866 &, 003 \\
Intercept & 2540,702 & 1 & 2540,702 & 36,494 &, 000 \\
Group & 552,985 & 1 & 552,985 & 7,943 &, 008 \\
Rel4 & 559,178 & 1 & 559,178 & 8,032 &, 007 \\
Error & 2575,922 & 37 & 69,620 & & \\
Total & 10292,000 & 40 & & & \\
Corrected Total & 3532,000 & 39 & & & \\
\hline \hline
\end{tabular}

a. $\mathrm{R}$ Squared $=, 271$ (Adjusted R Squared $=, 231)$

\section{Correlations}

\begin{tabular}{llrr}
\hline \hline & & $\begin{array}{c}\text { Snack amount } \\
\text { consumed by } \\
\text { mother }\end{array}$ & Rel4 \\
\hline Snack amount & Pearson Correlation & 1 &,- 338 \\
consumed by mother & Sig. (2-tailed) & 40 &, 033 \\
& N &,- 338 & 1 \\
\hline Rel4 & Pearson Correlation &, 033 & \\
& Sig. (2-tailed) & 40 & 40 \\
\hline \hline
\end{tabular}

*. Correlation is significant at the 0.05 level (2-tailed). 
Tests of Between-Subjects Effects

Dependent Variable: Snack amount consumed by mother

\begin{tabular}{lrrrrr}
\hline Source & $\begin{array}{c}\text { Type II Sum } \\
\text { of Squares }\end{array}$ & df & Mean Square & \multicolumn{1}{c}{ F } & \multicolumn{1}{c}{ Sig. } \\
\hline Corrected Model & $465,572^{2}$ & 3 & 155,191 & 1,973 &, 139 \\
Intercept & 475,191 & 1 & 475,191 & 6,041 &, 020 \\
Group &, 001 & 1 &, 001 &, 000 &, 998 \\
HEALTH & 12,823 & 1 & 12,823 &, 163 &, 689 \\
Group * HEALTH & 18,566 & 1 & 18,566 &, 236 &, 630 \\
Error & 2438,314 & 31 & 78,655 & & \\
Total & 8871,000 & 35 & & & \\
Corrected Total & 2903,886 & 34 & & & \\
\hline \hline
\end{tabular}

a. $\mathrm{R}$ Squared $=, 160$ (Adjusted R Squared $=, 079$ )

\section{Tests of Between-Subjects Effects}

Dependent Variable: Snack amount consumed by mother

\begin{tabular}{lcrrrr}
\hline \hline Source & $\begin{array}{c}\text { Type III Sum } \\
\text { of Squares }\end{array}$ & df & Mean Square & \multicolumn{1}{c}{ F } & \multicolumn{1}{c}{ Sig. } \\
\hline Corrected Model & $494,234^{2}$ & 2 & 247,117 & 3,010 &, 061 \\
Intercept & 3134,393 & 1 & 3134,393 & 38,177 &, 000 \\
Group & 254,234 & 1 & 254,234 & 3,097 &, 087 \\
Gen & 97,334 & 1 & 97,334 & 1,186 &, 283 \\
Error & 3037,766 & 37 & 82,102 & & \\
Total & 10292,000 & 40 & & & \\
Corrected Total & 3532,000 & 39 & & & \\
\hline \hline
\end{tabular}

a. R Squared $=, 140$ (Adjusted R Squared $=, 093$ )

\section{Tests of Between-Subjects Effects}

Dependent Variable: Snack amount consumed by mother

\begin{tabular}{lrrrrr}
\hline \hline Source & $\begin{array}{c}\text { Type III Sum } \\
\text { of Squares }\end{array}$ & df & Mean Square & \multicolumn{1}{c}{ F } & \multicolumn{1}{c}{ Sig. } \\
\hline Corrected Model & $643,646^{2}$ & 2 & 321,823 & 4,123 &, 024 \\
Intercept & 22,459 & 1 & 22,459 &, 288 &, 595 \\
Group & 396,900 & 1 & 396,900 & 5,084 &, 030 \\
ChiAge & 246,746 & 1 & 246,746 & 3,161 &, 084 \\
Error & 2888,354 & 37 & 78,064 & & \\
Total & 10292,000 & 40 & & & \\
Corrected Total & 3532,000 & 39 & & & \\
\hline \hline
\end{tabular}

a. $\mathrm{R}$ Squared $=, 182$ (Adjusted R Squared $=, 138$ ) 
The Effect of Making a Derived Food Choice

\section{Correlations}

\begin{tabular}{llrr}
\hline \hline & & $\begin{array}{c}\text { Snack amount } \\
\text { consumed by } \\
\text { mother }\end{array}$ & Age of Child \\
\hline $\begin{array}{l}\text { Snack amount } \\
\text { consumed by mother }\end{array}$ & Pearson Correlation & 1 &, 264 \\
& Sig. (2-tailed) & &, 099 \\
& N & 40 & 40 \\
\hline Age of Child & Pearson Correlation &, 264 & 1 \\
& Sig. (2-tailed) &, 099 & \\
& N & 40 & 40 \\
\hline \hline
\end{tabular}

\section{Tests of Between-Subjects Effects}

Dependent Variable: Snack amount consumed by mother

\begin{tabular}{lrrrrr}
\hline Source & $\begin{array}{c}\text { Type II Sum } \\
\text { of Squares }\end{array}$ & df & Mean Square & \multicolumn{1}{c}{ F } & Sig. \\
\hline Corrected Model & $405,329^{2}$ & 3 & 135,110 & 1,556 &, 217 \\
Intercept & 149,462 & 1 & 149,462 & 1,721 &, 198 \\
Group & 27,203 & 1 & 27,203 &, 313 &, 579 \\
Group * MoAge & 3,311 & 1 & 3,311 &, 038 &, 846 \\
MoAge & 3,625 & 1 & 3,625 &, 042 &, 839 \\
Error & 3126,671 & 36 & 86,852 & & \\
Total & 10292,000 & 40 & & & \\
Corrected Total & 3532,000 & 39 & & & \\
\hline \hline
\end{tabular}

a. $\mathrm{R}$ Squared $=, 115$ (Adjusted R Squared $=, 041)$

\section{Tests of Between-Subjects Effects}

Dependent Variable: Snack amount consumed by mother

\begin{tabular}{lrrrrr}
\hline Source & $\begin{array}{c}\text { Type II Sum } \\
\text { of Squares }\end{array}$ & df & Mean Square & \multicolumn{1}{c}{ F } & \multicolumn{1}{c}{ Sig. } \\
\hline Corrected Model & $563,836^{2}$ & 3 & 187,945 & 2,280 &, 096 \\
Intercept & 729,068 & 1 & 729,068 & 8,843 &, 005 \\
Group & 346,965 & 1 & 346,965 & 4,208 &, 048 \\
NoChild &, 504 & 1 &, 504 &, 006 &, 938 \\
Group *NoChild & 160,806 & 1 & 160,806 & 1,950 &, 171 \\
Error & 2968,164 & 36 & 82,449 & & \\
Total & 10292,000 & 40 & & & \\
Corrected Total & 3532,000 & 39 & & & \\
\hline \hline
\end{tabular}

a. $\mathrm{R}$ Squared $=, 160$ (Adjusted R Squared $=, 090)$ 


\section{Tests of Between-Subjects Effects}

Dependent Variable: Snack amount consumed by mother

\begin{tabular}{lcrrrr}
\hline Source & $\begin{array}{c}\text { Type III Sum } \\
\text { of Squares }\end{array}$ & df & Mean Square & \multicolumn{1}{c}{ F } & \multicolumn{1}{c}{ Sig. } \\
\hline Corrected Model & $405,941^{2}$ & 2 & 202,970 & 2,402 &, 104 \\
Intercept & 2618,007 & 1 & 2618,007 & 30,987 &, 000 \\
Group & 405,288 & 1 & 405,288 & 4,797 &, 035 \\
MarStatus & 9,041 & 1 & 9,041 &, 107 &, 745 \\
Error & 3126,059 & 37 & 84,488 & & \\
Total & 10292,000 & 40 & & & \\
Corrected Total & 3532,000 & 39 & & & \\
\hline \hline
\end{tabular}

a. $\mathrm{R}$ Squared $=, 115$ (Adjusted $\mathrm{R}$ Squared $=, 067$ )

\section{Tests of Between-Subjects Effects}

Dependent Variable: Snack amount consumed by mother

\begin{tabular}{lrrrrr}
\hline Source & $\begin{array}{c}\text { Type III Sum } \\
\text { of Squares }\end{array}$ & df & Mean Square & \multicolumn{1}{c}{ F } & \multicolumn{1}{c}{ Sig. } \\
\hline Corrected Model & $616,314^{2}$ & 3 & 205,438 & 2,537 &, 072 \\
Intercept & 1744,823 & 1 & 1744,823 & 21,543 &, 000 \\
Group & 46,653 & 1 & 46,653 &, 576 &, 453 \\
Group * WeightHIGH &, 571 & 1 &, 571 &, 007 &, 934 \\
WeightHIGH & 218,411 & 1 & 218,411 & 2,697 &, 109 \\
Error & 2915,686 & 36 & 80,991 & & \\
Total & 10292,000 & 40 & & & \\
Corrected Total & 3532,000 & 39 & & & \\
\hline \hline
\end{tabular}

a. R Squared $=, 174$ (Adjusted R Squared $=, 106$ )

\section{Tests of Between-Subjects Effects}

Dependent Variable: Snack amount consumed by mother

\begin{tabular}{lrrrrr}
\hline Source & $\begin{array}{c}\text { Type II Sum } \\
\text { of Squares }\end{array}$ & df & Mean Square & \multicolumn{1}{c}{ F } & \multicolumn{1}{c}{ Sig. } \\
\hline Corrected Model & $591,926^{2}$ & 3 & 197,309 & 2,416 &, 082 \\
Intercept & 1439,136 & 1 & 1439,136 & 17,622 &, 000 \\
Group & 9,597 & 1 & 9,597 &, 118 &, 734 \\
Group * BMI & 13,377 & 1 & 13,377 &, 164 &, 688 \\
BMI & 192,402 & 1 & 192,402 & 2,356 &, 134 \\
Error & 2940,074 & 36 & 81,669 & & \\
Total & 10292,000 & 40 & & & \\
Corrected Total & 3532,000 & 39 & & & \\
\hline \hline
\end{tabular}

a. $R$ Squared $=, 168$ (Adjusted R Squared $=, 098)$ 
The Effect of Making a Derived Food Choice

Tests of Between-Subjects Effects

Dependent Variable: Snack amount consumed by mother

\begin{tabular}{lrrrrr}
\hline Source & $\begin{array}{c}\text { Type II Sum } \\
\text { of Squares }\end{array}$ & df & Mean Square & \multicolumn{1}{c}{ F } & \multicolumn{1}{c}{ Sig. } \\
\hline Corrected Model & $398,933^{2}$ & 3 & 132,978 & 1,528 &, 224 \\
Intercept & 950,102 & 1 & 950,102 & 10,917 &, 002 \\
Group & 55,477 & 1 & 55,477 &, 637 &, 430 \\
TimeMeallnn & 1,873 & 1 & 1,873 &, 022 &, 884 \\
Group * TimeMeallnn &, 069 & 1 &, 069 &, 001 &, 978 \\
Error & 3133,067 & 36 & 87,030 & & \\
Total & 10292,000 & 40 & & & \\
Corrected Total & 3532,000 & 39 & & & \\
\hline \hline
\end{tabular}

a. $\mathrm{R}$ Squared $=, 113$ (Adjusted R Squared $=, 039$ )

\section{Anova for employment}

ANOVA

Snack amount consumed by mother

\begin{tabular}{lrrrrr}
\hline \hline & $\begin{array}{l}\text { Sum of } \\
\text { Squares }\end{array}$ & df & Mean Square & \multicolumn{1}{c}{ F } & Sig. \\
\hline Between Groups & 382,871 & 2 & 191,436 & 2,249 &, 120 \\
Within Groups & 3149,129 & 37 & 85,112 & & \\
Total & 3532,000 & 39 & & & \\
\hline \hline
\end{tabular}




\section{The Effect of Making a Derived Food Choice}

\section{References}

Brehm, J. W. (1966), Theory of Psychological Reactance, Burlington, MA: Academic Press.

Brooks, D. (Speaker). (2011). The Social Animal: TED talks.

Carver, Charles S. and Michael F. Scheier (1998), On the SelfRegulation of Behavior, New York: Cambridge University Press.

Chakravarti, A., Janiszewski, C., \& Ülkümen, G. (2006). The neglect of prescreening information. Journal of Marketing Research, 43(November), 642-653.

Chandon, Pierre and Brian Wansink (2007), "The Biasing Health Halos of Fast-Food Restaurant Health Claims: Lower Calorie Estimations and Higher Side-Dish Consumption Intentions," Journal of Consumer Research, 34 (October), 301-14.

Fishbach, A. \& Dhar, R. (2005), "Goals as Excuses or Guides: The Liberating Effect of Perceived Goal Progress on Choice," Journal of Consumer Research, 32 (December), 370-77.

Fishbach, A., \& Finkelstein, S. R. (2010). When healthy food makes you hungry. Journal of consumer Research, 97, doi: 10.1086/652248

Fishbach, A. \& Zhang, Y. (2008), "Together or Apart: When Goals and Temptations Complement versus Compete," Journal of Personality and Social Psychology, 94 (April), 547-59.

Fo"rster, Jens, Nira Liberman, and Ronald S. Friedman (2007), "Seven Principles of Goal Activation: A Systematic Approach to Distinguishing Goal Priming from Priming of Non-goal Constructs," Personality and Social Psychology Review, 11 (August), 21133

Kahn, Barbara E. and Brian Wansink (2004), "The Influence of Assortment Structure onPerceived Variety and Consumption Quantities," Journal of Consumer Research,30 (4), 519-33.

Khan, U. \& Dhar, R. (2006), "Licensing Effect in Consumer Choice," Journal of Marketing Research, 43 (May), 259-66.

Monin, B. \& Miller, D. T. (2001), "Moral Credentials and the Expression of Prejudice," Journal of Personality and Social Psychology, 81 (July), 33-43.

National Institute for Health and Clinical Excellence (NICE), (2008). Maternal and Child Nutrition. Retrieved http://www.nice.org.uk/nicemedia/live/11943/40097/40097.pdf.

Neely, James H. (1977), "Semantic Priming and Retrieval from Lexical Memory: Roles of Inhibitionless Spreading Activation and Limited-Capacity Attention," Journal of Experimental Psychology: General, 106 (September), 226-54.

Polivy, J. \& Herman, C. P. (1985), "Dieting as a Problem in Behavioral Medicine," in Advances in Behavioral Medicine, ed. Edward S. Katkin and Stephen B. Manuck, New York: SAI, 1-37. 


\section{The Effect of Making a Derived Food Choice}

Shiv, B., \& Fredorikhin, A. (1999), "Heart and Mind in Conflict: the Interplay of Affect and Cognition in Consumer Decision Making". Journal of Consumer Research, The University of Chicago Press, 26, 278-292.

Statistisches Landesamt Rheinland-Pfalz. (2009). Körpergröße und -gewicht in Rheinland-Pfalz. Retrieved June 12, 2014, from https://www.statistik.rlp.de/fileadmin/dokumente/nach.../Gewicht.pdf

UNICEF, (2010). Early Child Development: A treasure box of activities. Activity Guide. New York: UNICEF. http://www.unicef.org/videoaudio/PDFs/Activity_Guide_EnglishFINAL.pdf

Van Osselaer, Stijn M. J., van (2008), "Associative Learning and Consumer Decisions," in Handbook of Consumer Psychology, Vol. 1, ed. Curtis P. Haugtvedt, Paul M. Herr, and Frank R. Kardes, Mahwah, NJ: Erlbaum, 699-729.

World Health Organisation (WHO), (2001). Mental Health and Psychosocial well-being among children in Severe Food Shortage Situations

Wilcox, K., Block, L., J. Fitzsimons, G. J., \& Vallen, B. (2009), "Vicarious Goal Fulfillment: When the Mere Presence of a Healthy Option Leads to an Ironically Indulgent Decision," Journal of Consumer Research 36 (3), 380-393. 